\title{
Report 41164R09
}

\section{ADAPTIVE FULL-SPECTRUM SOLAR ENERGY SYSTEMS \\ Cross-Cutting $R \& D$ on adaptive full-spectrum solar energy systems for more efficient and affordable use of solar energy in buildings and hybrid photobioreactors}

Final Technical Report

Byard D. Wood, Project Director Mechanical and Aerospace Engineering

Utah State University

Logan, Utah 84322-4130
Kwang Kim, Principal Investigator

Mechanical Engineering - 312

University of Nevada

Reno, NV 89577

Jeff D. Muhs, Co-Principal Investigator

Oak Ridge National Laboratory

P.O. Box 2008

Oak Ridge, TN 37831-6074

\section{PREPARED FOR}

\section{NATIONAL ENERGY TECHNOLOGY LABORATORY} THE UNITED STATES DEPARTMENT OF ENERGY

DOE Award Number DE-FC26-01NT41164

Energy Crosscutting Science Initiative Office of Energy Efficiency and Renewable Energy 


\begin{abstract}
This RD\&D project is a multi-institutional effort to develop a hybrid solar lighting (HSL) system that transports daylight from a paraboloidal dish concentrator to a luminaire via a bundle of polymer fiber optics. The luminaire can be a device to distribute sunlight into a space for the production of algae for $\mathrm{CO}_{2}$ sequestration or it can be a device that is a combination of daylighting and electric lighting for space/task lighting. In this project, the sunlight is collected using a one-meter paraboloidal concentrator dish with two-axis tracking. For the third generation (beta) system, the secondary mirror is an ellipsoidal mirror that directs the visible light into a bundle of $3 \mathrm{~mm}$ diameter fibers. The IR spectrum is filtered out to minimize unnecessary heating at the fiber entrance region. This report describes the major
\end{abstract}

achievements from this research that began in August 2001:

\title{
DISCLAIMER
}

This Final Report was prepared as an account of work sponsored by an agency of the United States Government. Neither the United States Government nor any agency thereof, nor any of their employees, makes any warranty, express or implied, or assumes any legal liability or responsibility for the accuracy, completeness, or usefulness of any information, apparatus, product or process disclosed, or represents that its use would not infringe privately owned rights. Reference herein to any specific commercial product, process, or service by trade name, trademark, manufacturer, or otherwise does not necessarily constitute or imply its endorsement, recommendation, or favoring by the United States Government or any agency thereof. The views and opinions of authors expressed herein do not necessarily state or reflect those of the United States Government or any agency thereof.

\section{PREFACE}

This project is part of the FY 2000 Energy Efficiency Science Initiative that emphasized CrossCutting R\&D in Solicitation No.: DE-PS36-00GO10500

This report is a joint effort between Oak Ridge National Laboratory and the University of Nevada, Reno, and as such it satisfies the reporting requirements for the University and ORNL as the M\&O for this project. The reporting period is from August 2, 2001 through August 30, 2006. This competitively funded project was funded for three years beginning August 2, 2001. However, during the course of this work there were two prolonged procurement delays. One was related to the mold for manufacturing the mirrors and the other was related to a duel mirror tracking system. Two no-cost time extensions were approved to allow the project to be completed. 


\section{EXECUTIVE SUMMARY}

This RD\&D project is a multi-year team effort to develop a hybrid solar lighting (HSL) system that transports daylight from a paraboloidal dish concentrator to a luminaire via a bundle of small core or large core polymer fiber optics. The luminaire can be a device to distribute sunlight into a space for the production of algae for $\mathrm{CO}_{2}$ sequestration or it can be a device that is a combination of daylighting and electric lighting for space/task lighting. In this project, the sunlight is collected using a one-meter paraboloidal concentrator dish with two-axis tracking.

During the first budget period (August 2001 - April 2003) a bench mark prototype system was developed and evaluated to determine technical feasibility of using full-spectrum solar energy systems to enhance the overall sunlight utilization in buildings and biomass production rates of photobioreactors.

During the second budget period (May 2003 - April 2004), emphasis was placed on determining those aspects of the solar lighting system that characterize performance efficiency, reliability, durability and ultimately minimum cost potential. The major accomplishment was the second generation (alpha) system for which the secondary mirror is an ellipsoidal mirror that directs the visible light into a bundle of smallcore fibers.

During the third budget period (May 2004 - December 2006), emphasis was placed on component designs that will result in significant cost reductions as well as identifying potential niche applications for the HSL technology.

The significant outcomes presented in this Final Report are due to the interdisciplinary capabilities of researchers from six universities (University of Nevada, Reno; Utah State University, Ohio University, Rensselaer Polytechnic Institute, University of Arizona, and University of Wisconsin); four industry partners (Honeywell Technology Center, JX Crystals, Inc.; Science Applications International Corp., and 3M Company); and the Department of Energy's Oak Ridge National Laboratory (ORNL).

The research team achieved two major objectives:

1) Determine technical feasibility and economic viability of using full-spectrum solar energy systems to enhance the overall sunlight utilization in buildings and biomass production rates of photobioreactors.

2) Design solar collector/receiver with large-core optical fiber light distribution system that efficiently delivers the visible portion of direct sunlight to multiple remote locations for illumination purposes while simultaneously converting the IR portion of the solar spectrum into electricity using ideally suited infrared thermophotovoltaics.

\section{Major Outcomes}

1) Two notable patents were obtained: ORNL US Patent 6603069, Adaptive Full-Spectrum Solar Energy System, 18 Sept 2001, licensed to SunLight Diirect LLC; and Ohio University US Patent 6667171, Enhanced Practical Photosynthesis CO2 Mitigation, 23 Dec 2003, licensed to GreenShift Corp.

2) Work accomplished by one doctoral candidate and eight master's students resulted in degrees earned; refereed archival papers were published in eight journals, and 15 papers were presented at professional conferences. 
3) $R \& D$ Magazine named the project one of the top 100 inventions of 2006.

4) Oak Ridge's Hybrid Solar Laboratory hosts the first lab of its kind where occupants can compare and visualize the value of sunlight.

5) Utah State University received a Utah Science, Technology, and Research Initiative (USTAR) grant to establish a biofuels R\&D program built around the solar bioreactor developed in this project. This project integrates with USU patented anaerobic digestion bioreactor for producing biogas (methane and $\mathrm{CO}_{2}$ )

\section{Additional Achievements}

Progress was made toward all performance targets for the solar collector/receiver. Milestones were achieved except those associated with long-term system operation. Milestones included:

1) Delivered 50,000 lumens $/ \mathrm{m} 2$ (peak) of collected sunlight to interior space. The goal was $56 \%$ overall system efficiency - the project delivered $50 \%$ of available lumens in incident sunlight to interior spaces.

2) Completed colorimetry analysis of delivered sunlight.

3) Raytrace analysis for several luminaries.

4) Tested high-flux of optical fibers.

5) Conducted mechanical endurance tests on fibers.

6) Investigated non-lighting applications.

7) Created a fundamental model for light transmission.

Conclusions drawn from extensive photobioreactor experimentation include:

1) Thermophilic cyanobacteria can be used to remove $\mathrm{CO}_{2}$ from coal-fired power plants in a practical manner.

2) Use of fiber optics allows for more production of algae per unit area than any other photobioractor.

3) Correlation between available sunlight and algal production indicates light is being used efficiently in the photobioreactor.

4) Sunlight is the only feasible means of providing light to microalgae for biomass or $\mathrm{CO}_{2}$ sequestration.

\section{Conclusion}

This project demonstrates that concentrated visible sunlight can be collected and transported efficaciously to a luminaire using polymer fiber optics and the infrared solar energy can be separated and directed to a thermophotovolataic array for electrical power generation. That power can be used to operate $\mathrm{CO}_{2}-$ mitigating plants at industrial sites and the algal by-products can be converted into other energy and useful byproducts.

Beta tests, under the auspices of ORNL and SunLight Direct, are underway in eight states and Washington, D.C. Collaborating groups include San Diego State University, Utah State University, and North Carolina State University; retail outlets in Texas and Tennessee, research firms in Washington State and California, governmental agencies in California, Tennessee, Washington, D.C., and New York. 
EXECUTIVE SUMMARY.$\ldots \ldots \ldots \ldots \ldots \ldots \ldots \ldots \ldots \ldots \ldots \ldots$, Iii

LIST OF TABLES................................. Vi

LIST OF FIGURES. $\ldots \ldots \ldots \ldots \ldots \ldots \ldots \ldots \ldots \ldots \ldots \ldots \ldots \ldots \ldots \ldots \ldots, \quad \mathrm{Vi}$

PARTICIPATING ORGANIZATIONS....................... viii

$1 \quad$ INTRODUCTION..................................... 1

2 MAJOR OUTCOMES................................. 2

$2.1 \quad$ PATENTS......................................... 2

2.2 COMMERCIALIZATION............................... 3

2.3 NEW R\&D ACTIVITIES............................. 4

2.4 ARCHIVAL PUBLICATIONS............................ 4

2.5 CONFERENCE PROCEEDINGS.......................... 5

$2 . .6 \quad$ GRADUATE DEGREES............................... 6

2..7 HSL BETA SYSTEM AND SYSTEM PERFORMANCE TARGETS. ....... 6

3. PATH TO LOW COST HSL SYSTEM FOR BUILDING APPLICATIONS ... 8

4 PHOTOBIOREACTOR DEVELOPMENT PROGRESS $\ldots \ldots \ldots \ldots \ldots \ldots . . \ldots \ldots$

5 CYANOBACTERIAL SPECIES FOR CO2 MITIGATION ............. 23

6 DESCRIPTION OF TRNSYS SYSTEM MODEL $\ldots \ldots \ldots \ldots \ldots \ldots \ldots .29$

7 OVERALL PROJECT SUMMARY STATEMENT................ 32

\begin{tabular}{l|l}
8 & MAJOR CONTRIBUTIONS OF EACH PARTNER.................. 34
\end{tabular}

$9 \quad$ REFERENCES...................................... 35

10 DISTRIBUTION................................... 36 


\section{LIST OF TABLES}

Table 1 Environmental, optical, operational, and mechanical requirements for HSL system.

Table 2 Major components of low cost HSL system

Table 3 Economic summary of TRNSYS simulations for active collector area of $1.7 \quad 31$ $\mathrm{m}^{2}$.

Table $4 \quad$ Economic summary of TRNSYS simulations for active collector area of $1.0 \quad 32$ $\mathrm{m}^{2}$

\section{LIST OF FIGURES}

Fig. 1 Beta system that is manufactured and marketed by Sunlight Direct, LLC. 7

Fig. 2 Picture of hybrid luminaire $\quad 7$

Fig. 3 Maximum Allowable Slope Error to Deliver $1500 \mathrm{~W}$ of Power to a 5 -cm 10 Diameter Receiver

Fig. 4 Optical Quality of Pressed Steel Satellite Dish 11

Fig. $5 \quad$ Breakdown of Costs of Prototype Dish/Tracker System 13

Fig. 6 Prototype low-cost dish/tracker system based on a commercially-available satellite dish reflector and simple, low-cost tracker components. The single-unit cost of the prototype system was about $\$ 1300$ (\$520/sq.m), with potential for significant additional reductions in quantity production. This prototype demonstrates the potential to develop a cost-effective dish/tracker system that ensures economic feasibility of this system.

Fig. 7 Solar bioreactor concept for $\mathrm{CO} 2$ sequestration using microalgae growing in 17 vertical biofilms

Fig. $8 \quad$ Populated substrates showing capillary transport of water $\quad 18$

Fig. $9 \quad$ Solar Collector Mounted Above Pilot-Scale Bioreactor $\quad 18$

$\begin{array}{ll}\text { Fig. } 10 \text { Lighting panels with fiber optic leads } & 19\end{array}$

Fig. 11 Membrane populated with microalgae 20

Fig. 12 Membrane washed with the harvesting system 20

Fig. 13 Preliminary Productivity Data 21

Fig. 14 Repeated Productivity Results 21 
Fig. 15 Cost of one ton of $\mathrm{CO}_{2}$ removed as a function of photon conversion efficiency

Fig. 16 A micrograph of SC2 (left) and SC2 maintained in flask cultures (right).

Fig. 17 Apparatus for the heated water-bath experiment

Fig. 18 Time course of dry weight changes of Chlorella vulgaris under two light conditions, ambient $\mathrm{CO} 2$ and $25^{\circ} \mathrm{C}$ temperature (left), and comparison of the final dry weight data between the two light conditions (right). The experiments were repeated twice. The error bars show standard errors, and there was no statistical significance between the two light conditions at 95\% confidence level.

Fig. 19 Apparatus for the heated water-bath experiment with elevated CO2 concentration

Fig. 20 Dry weight changes of SC2 over time at $5 \%(\mathrm{v} / \mathrm{v}) \mathrm{CO}_{2}$ and light intensity of $250 \mu \mathrm{mol} \mathrm{m}{ }^{-2} \mathrm{~s}^{1}$. Flow rate of $\mathrm{CO}_{2}$ gas was 0.0021 gas $^{-1}$ medium $\mathrm{min}^{-1}$. Data are based on average of three samples. Error bars show standard deviations

Fig. 21 Dry weight changes of SC2 over time at $5 \%(\mathrm{v} / \mathrm{v}) \mathrm{CO}_{2}$ and light intensity of $250 \mu \mathrm{mol} \mathrm{m} \mathrm{m}^{-2} \mathrm{~s}^{-1}$. Flow rate of $\mathrm{CO}_{2}$ gas was 0.0021 gas $^{-1}$ medium $\mathrm{min}^{-1}$. Data are based on average of three samples. Error bars show standard deviations.

Fig. 22 Dry weight changes of SC2 over time for three light intensities in $\mathrm{mol} \mathrm{m}^{-2} \mathrm{~s}^{-}$ 1. Flow rate of $\mathrm{CO}_{2}$ gas was 0.0021 gas $^{-1}$ medium $\mathrm{min}^{-1}$. Data are based on an average of two samples. Error bars show standard deviations.

Fig. 23 Carbon assimilation rates of $\mathrm{SC} 2$ for three light intensities and three $\mathrm{CO}_{2}$ gas conditions. Data were based on average of two replications. Each replication had two samples.

Fig. 24 Schematics of photobioreactor.

Fig. 25 Operation of membrane photobioreactor. 


\section{PARTICIPATING ORGANIZATIONS}

\begin{tabular}{|c|c|c|}
\hline Organization & Abbreviation & $\begin{array}{c}\text { Principal Investigators } \\
\text { \& Co-Authors }\end{array}$ \\
\hline $\begin{array}{l}\text { Utah State University } \\
\text { Mechanical and Aerospace Engineering } \\
\text { Logan, UT } 84322-4130\end{array}$ & USU & $\begin{array}{l}\text { Byard Wood } \\
\text { Dan Dye }\end{array}$ \\
\hline $\begin{array}{l}\text { University of Nevada, Reno } \\
\text { Mechanical Engineering } \\
\text { Mail Stop } 312 \\
\text { Reno, NV } 89557\end{array}$ & UNR & Allen Gates \\
\hline $\begin{array}{l}\text { Oak Ridge National Lab } \\
\text { P.O. Box 2009, MS-8058 } \\
\text { Oak Ridge, TN } 32831\end{array}$ & ORNL & $\begin{array}{l}\text { Jeff Muhs } \\
\text { Melissa Voss Lapsa } \\
\text { David L. Beshears } \\
\text { Duncan Earl }\end{array}$ \\
\hline $\begin{array}{l}\text { Ohio University } \\
\text { Dept. of Mechanical Engineering } \\
248 \text { Stocker Center } \\
\text { Athens, OH 45701-2979 }\end{array}$ & Ohio & David Bayless \\
\hline $\begin{array}{l}\text { Rensselaer Polytechnic Institute } \\
\text { Lighting Research Center } \\
21 \text { Union Street } \\
\text { Troy, NY 12180-3352 }\end{array}$ & RPI & $\begin{array}{l}\text { Nadarajah Narendran } \\
\text { Ramesh Raghavan }\end{array}$ \\
\hline $\begin{array}{l}\text { Science Application International Corporation } \\
9455 \text { Towne Centre Drive } \\
\text { San Diego, California } 92121\end{array}$ & SAIC & $\begin{array}{l}\text { Robin Taylor } \\
\text { Roger Davenport }\end{array}$ \\
\hline $\begin{array}{l}\text { University of Arizona } \\
\text { Dept. of Agricultural and Biosystems } \\
\text { Engineering } \\
507 \text { Shantz Building } \\
\text { Tucson, AZ } 85721\end{array}$ & UA & Joel Cuello \\
\hline $\begin{array}{l}\text { University of Wisconsin } \\
\text { Solar Energy Lab } \\
\text { 1500 Johnson Dr. } \\
\text { Madison, WI } 53706\end{array}$ & UW & $\begin{array}{l}\text { William Beckman } \\
\text { Sandy Klein }\end{array}$ \\
\hline
\end{tabular}

The contributions of each of these individuals in carrying out this project and the preparation of this report are gratefully acknowledged. 


\section{INTRODUCTION}

This research project addressed key scientific hurdles associated with adaptive, full-spectrum solar energy systems and associated applications in commercial buildings and new hybrid solar photobioreactors. The goal of the project was to demonstrate that full-spectrum solar energy systems can more than double the affordability of solar energy in commercial buildings and in hybrid solar photobioreactors used in $\mathrm{CO}_{2}$ mitigation, and that they can compete favorably with existing alternatives.

Adaptive, full-spectrum solar energy systems represent a unique, systems-level approach to solar energy that holds the promise of dramatically improving its end-use efficiency and affordability in two ways. First, it more efficiently uses different portions of the solar spectrum simultaneously for multiple end-use applications such as solar lighting and distributed-power generation, e.g., combined solar light and power. Second, it continually optimizes solar energy end-use efficiency by adapting to real-time changes in enduse needs and external factors such as real-time electricity prices, solar availability, and ancillary services.

The significant outcomes presented in this Final Report are due to the interdisciplinary capabilities of researchers from six universities (University of Nevada, Reno; Utah State University, Ohio University, Rensselaer Polytechnic Institute, University of Arizona, and University of Wisconsin); four industry partners (Honeywell Technology Center, JX Crystals, Inc.; Science Applications International Corp., and 3M Company); and the Department of Energy's Oak Ridge National Laboratory (ORNL). The primary researchers are listed on page ix

To realize these outcomes, the following key scientific hurdles were addressed:

1. Determine technical feasibility of using full-spectrum solar energy systems to enhance the overall sunlight utilization in buildings and biomass production rates of photobioreactors. This was accomplished by developing and testing a benchmark prototype system.

2. Determine the commercial viability of using full-spectrum solar energy systems to enhance the overall sunlight utilization in buildings and biomass production rates of photobioreactors. This was accomplished by determining those characteristics that characterize performance efficiency, reliability, durability, and ultimately minimum cost potential of the solar collector and sunlight distribution subsystem.

3. Demonstrate the HSL technology in a building application and a photobioreactor application. The emphasis in developing the demonstration systems was to meet performance objectives and provide a path for market competitiveness.

This final report will emphasize research that has not been documented in the following eight semiannual technical reports that were previously sent to NETL ADD Document Control.

\begin{tabular}{|c|ll|}
\hline Report No. & & \multicolumn{1}{c|}{ Contents } \\
\hline 41164R01 & $>$ & Bench-mark solar collector/receiver \\
Aug 2001- Mar 2002 & & \\
& & \\
\hline 41164R02 & $>$ & Bench-mark solar collector/receiver performance \\
Apr - Aug 2002 & $>$ & Thermal management model for 12 mm PMMA optical fiber \\
& $>$ & Daylight and productivity literature review \\
& $>$ & HSL luminaire design characteristics \\
& & \\
\hline 41164R03 & $>$ & IR photovoltaic receiver and test results \\
Aug 2002- Apr 2003 & $>$ TRNSYS simulation model of HSL system and results \\
\hline
\end{tabular}




\begin{tabular}{|c|c|}
\hline & $\begin{array}{l}>\text { Bending fatigue tests for } 12 \mathrm{~mm} \text { optical fibers } \\
>\text { Non-imaging devices for uniform irradiance at fiber entrance }\end{array}$ \\
\hline $\begin{array}{c}\text { 41164R04 } \\
\text { May } 2002-\text { Aug } 2003\end{array}$ & $\begin{array}{l}>\text { TRNSYS model improvements } \\
>\text { Bioreactor design considerations } \\
>\text { Bioreactor lighting panels for vertical biofilms }\end{array}$ \\
\hline $\begin{array}{c}41164 R 05 \\
\text { Sep 2003 - Jan 2004 }\end{array}$ & $\begin{array}{l}\text { Thermophotovoltaic module testing results } \\
\text { TRNSYS chromaticity model } \\
>\text { Bioreactor redesign results } \\
>\text { Thermophilic algal species and lab scale bioreactor }\end{array}$ \\
\hline $\begin{array}{c}41164 R 06 \\
\text { Feb 2004 - Jul } 2004\end{array}$ & $\begin{array}{l}>\text { TRNSYS model development } \\
>\text { High lumen test apparatus } \\
>\text { Thermal management of optical fiber bundle } \\
>\text { Photobioreactor experimental results }\end{array}$ \\
\hline $\begin{array}{c}41164 \mathrm{R} 07 \\
\text { Aug 2004 - Jan } 2005\end{array}$ & $\begin{array}{l}>\text { Fiber optic bundle thermal management experiments } \\
>\text { Photobioreactor testing }\end{array}$ \\
\hline $\begin{array}{c}\text { 41164R08 } \\
\text { Feb 2005 - Jan } 2006\end{array}$ & $\begin{array}{l}>\text { Potential applications for HSL luminaires } \\
>\text { Luminaire designs } \\
>\text { Daylight and Productivity }\end{array}$ \\
\hline
\end{tabular}

\section{MAJOR OUTCOMES}

\subsection{PATENTS}

US patent no. 6603069, Sept. 18, 2001, “Adaptive full spectrum solar energy system,” Jeffrey D. Muhs and Dennis D. Earl, owned by Oak Ridge National Laboratory (ORNL).

Abstract: An adaptive full spectrum solar energy system having at least one hybrid solar concentrator, at least one hybrid luminaire, at least one hybrid photobioreactor, and a light distribution system operably connected to each hybrid solar concentrator, each hybrid luminaire, and each hybrid photobioreactor...

Although this patent was processed before this grant got started, it is listed here for completeness since it describes the concept that formed the basis for this project.

US Patent no. 6,667,171, Dec. 23, 2003, "Enhanced practical photosynthetic $\mathrm{CO}_{2}$ mitigation", Bayless; David J. (Athens, OH); Vis-Chiasson; Morgan L. (Athens, OH); Kremer; Gregory G. (Athens, OH) Owned by Ohio University (Athens, $\mathrm{OH}$ )

Abstract: This process is unique in photosynthetic carbon sequestration. An on-site biological sequestration system directly decreases the concentration of carbon-containing compounds in the emissions of fossil generation units. In this process, photosynthetic microbes are attached to a growth 
surface arranged in a containment chamber that is lit by solar photons. A harvesting system ensures maximum organism growth and rate of $\mathrm{CO}_{2}$ uptake...

This patent was the result of work supported in part by this grant.

\subsection{COMMERCIALIZATION}

Sunlight Direct, LLC is a spin out company from ORNL based on the HSL technology developed in part during the course of this project. Sunlight Direct, LLC was formed in 2004 with the mission of "enabling" alternative energy solutions. Using a patented (US patent no. 6603069) solar collection platform that allows sunlight to be collected and controlled for various applications, Sunlight Direct is enabling alternative energy technologies in the fields of:

$>$ solar lighting

$>$ concentrated photovoltaics

$>$ photo-bioreactors for the production of biodiesel, hydrogen, and carbon sequestration

From its headquarters in Oak Ridge, TN, Sunlight Direct currently manufactures and installs the Hybrid Solar Lighting (HSL) system for commercial buildings which enables the wide-scale application of daylighting to commercial spaces. With initial applications in retail and office environments, this technology has the potential to be a disruptive force in the lighting market. With a value proposition that includes benefits associated with higher quality lighting (such as improved sales and productivity) in addition to energy savings, Sunlight Direct is breaking down past conceptions regarding the economic viability of solar technology while becoming a premier provider of high quality, energy efficient lighting to the commercial building sector. The success of this product is, in turn, enabling other technologies by reducing the cost and improving the performance of Sunlight Direct's multi-use Solar Collection platform. [www.sunlight-direct.com, December 2006]

Currently there are at least 10 units in operation across the country at San Diego State University, Pacific Northwest National Laboratory, Utah State University, Saramento Municipal Utility District, Aveda, Staples, Braden's Furniture, the American Museum of Science and Energy, Siskin Learning Center, and Oak Ridge National Laboratory, Another 15 are backlogged awaiting installation

GreenShift Corporation (OTC Bulletin Board: GSHF)has licensed the Ohio University patent (US Patent no. 6,667,171). GreenShift Corporation's corporate offices are located at 1 Penn Plaza, Suite 1612 New York, NY 10119. GreenShift develops and supports clean technologies and companies that facilitate the efficient use of natural resources and catalyze transformational environmental gains. GreenShift's companies own exclusive rights to many proprietary clean technologies and have combined annualized revenues of about $\$ 35$ million with EBITDA margins in excess of about 10\%. [www.greenshift.com, December 2006]

R\&D Magazine selected the hybrid solar lighting technology as one of the top 100 inventions for 2006 at its October 2006 R\&D 100 Awards banquet. For 44 years, the prestigious R\&D 100 Awards have been helping companies provide the important initial push a new product needs to compete successfully in the marketplace. The winning of an R\&D 100 Award provides a mark of excellence known to industry, government, and academia as proof that the product is one of the most innovative ideas of the year. [www.rdmag.com/awards.aspx, December 2006] 


\subsection{NEW R\&D ACTIVITIES}

In 2005, the State of Utah established the Utah Science, Technology and Research Economic Development Initiative (USTAR) in collaboration with Utah's business leaders, the Governor's Office, economic development leaders, key legislators, and university leaders. USTAR is designed to ensure that Utah has a large share of the jobs, businesses and economic development that will emerge from research and development in the genetics industry. To make that happen, the USTAR initiative will build, recruit and fund carefully-targeted, world-class science and technology research teams at its two research universities. These research teams will be housed in new research facilities with state-of-the-art laboratories, at the University of Utah and Utah State University. In addition, five Innovation Centers with close ties to the research teams, will be located at other higher education facilities to foster research and business creation all over the state. The funding approved at the 2006 legislative session will be used to recruit and fund the research teams and to construct the research facilities. The USTAR initiative is the top economic development priority for most of the state's business groups and associations because they recognize that the future is in science and technology.

The Utah State University proposal for a multidisciplinary USTAR Biofuels Initiative was approved for $\$ 6.5$ million over a five year period beginning January 1,2007. The USTAR Biofuels Team will continue the development of the solar bioreactor initiated in this project but with an emphasis on developing biofuels such methane, biodiesel, and hydrogen. Its goals are:

1) Establish a sustainable research team that will continuously develop new biomass feed stocks, develop high efficient feedstock production units, maximize product yields, and process the products into commercial biofuels and other commercial products that will provide the basis for economic development activities within the State of Utah.

2) Emphasize the development of a synergism between the Induced Blanket Reactor (IBR) anaerobic digester that produces biogas fuel and the Solar Bioreactor for growing microalgae to produce oil that is converted into biodiesel. The IBR provides $\mathrm{CO}_{2}$ and nutrients (primarily nitrogen and phosphorus) that are needed for the phototrophic microbes in the solar bioreactor.

The USTAR funds will be used to build new state-of-the-art research facilities for identifying and producing microbes for producing oil that can be processed into liquid and gaseous fuels.

\subsection{ARCHIVAL PUBLICATIONS}

1) CO2 Mitigation Using Thermophilic Cyanobacteria, E. Ono and J.L. Cuello, Journal of Biosystems Engineering, 95(4) 597-606, 2006.

2) Demonstration of Infrared-Photovoltaics for a Full-Spectrum Solar Energy System, D. Dye, B.D. Wood, L. Fraas, and J. Kretschmer, Journal of Solar Energy Engineering, Vol. 128, No. 1, pp 3033, 2006.

3) Carbon Dioxide Mitigation Using Thermophilic Cyanabacteria, E. Ono and J.L. Cuello, Journal of Biosystems Engineering, 96(1), 129-134, 2007

4) Feasibility Assessment of Open-Pond Microalgal CO2 Mitigation Technology with Implementation of the Kyoto Protocol, E. Ono and J.L. Cuello, Journal of Environmental Control in Biology, 42(3): 161-168, 2005.

5) Prediction of Light-Transmission Losses in Plastic Optical Fibers, Murat Tekelioglu and Byard D. Wood, Applied Optics, Vol. 44 No. 12, 20April2005. 
6) Analysis of a Full Spectrum Hybrid Lighting System, G.O. Schlegel, F.W. Burkholder, S.A. Klein, W.A. Beckman, B.D. Wood, J.D. Muhs, Solar Energy, Vol 76, pp 359-368, 2004.

7) Optical Design of an Infrared Non-Imaging Device for a Full-Spectrum Solar Energy System, D. Dye, B. Wood, L. Fraas, J. Muhs; Journal of Solar Energy Engineering, Vol. 126, No. 1, pp 676679, 2004.

8) Design Parameters of Solar Concentrating Systems for CO2-Mitigating Algal Photobioreactors, E. ONO and J.L. Cuello, Journal of Energy 29: 1651-1657, 2003.

\subsection{CONFERENCE PROCEEDINGS}

1) Demonstration of Infrared-Photovoltaics for a Full-Spectrum Solar Energy System, D. Dye, B.D. Wood, L. Fraas, and J. Kretschmer, Proceedings of the American Solar Energy Society, Annual Meeting SOLAR 2004, Portland, OR., July 9-14, 2004

2) Demonstration of Thermophotovoltaics for Full-Spectrum Solar Energy System, Dan Dye, Byard Wood, Lewis Fraas, Jeanette Kretschmer, Proceedings ASME International Solar Energy Conference Solar 2004, paper \# 65125, July 11-14, 2004

3) TRNSYS Modeling of a Hybrid Lighting System Building Energy Loads and Chromaticity Analysis, F.W. Burkholder, W.A. Beckman, S.A. Klein, and D.T. Reindl, Proceedings of American Solar Energy Society, Annual Meeting SOLAR 2004, Portland, OR., July 9-14, 2004.

4) Infrared Transmission Efficiency of Refractive and Reflective Non-Imaging Devices for a FullSpectrum Solar Energy System, D. Dye and B.D. Wood, Nonimaging Optics: Maximum Efficiency Light Transfer VII, Proceedings of SPIE Vol. 5185, 2003.

5) Non-Imaging Devices for Uniform Irradiance on Planar Surfaces for Parabolic Concentrators, D. Dye and Wood, B.D., Proceedings of the American Solar Energy Society, Annual Meeting SOLAR 2003, Austin, TX, 2003

6) Optical Design of an Infrared Non-Imaging Device for a Full- Spectrum Solar Energy System, D. Dye, B.D. Wood, L. Fraas, and J. Muhs, Proceedings of the ASME International Solar Energy Conference, Hawaii, 2003

7) Thermal Management of the Polymethylmethacrylate (PMMA) Core Optical Fiber for Use in Hybrid Solar Lighting, Murat Tekelioglu and Byard D. Wood, Proceedings ASME International Solar Energy Conference, March 2003

8) A TRNSYS Model of a Full Spectrum Hybrid Lighting System, G.O. Schlegel, S. A. Klein, W. A. Beckman, B. D. Wood, and J. D. Muhs, " ISES, June 14-19 Göteborg, Sweden (2003)

9) Full Spectrum Hybrid Lighting for Commercial Buildings, G.O. Schlegel, S.A. Klein, W.A. Beckman, B.D. Wood, J.D. Muhs "Paper ID RL5\#51 Right Light 5, Nice, France (May, 2002) 


\subsection{GRADUATE DEGREES}

Sadasivuni, Cherishma P. (MS 2007) Thesis: Design and Analysis of the Optics for Concentrating Sunlight onto a Fiber Optic Bundle, Utah State University

Cheadle, M. (MS 2006) Thesis: A Predictive Thermal Model of Heat Transfer in a Fiber Optic Bundle for a Hybrid Solar Lighting System, University of Wisconsin - Madison

Jones, Stephen J. (MS 2005) Report: Investigation of Hydraulic Sun Tracking System, University of Nevada - Reno

Zemke, Pete E. (MS 2005) Thesis Adaptation of Hybrid Solar Lighting Technology for Use in Solar Domestic Hot Water Systems, Utah State University

Tekelioglu, Murat (PhD 2005) Dissertation: Light Transmission for Polymer Fibers Using Skew and Meridional Rays, University of Nevada - Reno

Burkholder, F.W. (MS 2004) Thesis: TRNSYS Modeling of a Hybrid Lighting System: Energy Savings and Colorimetry Analysis, University of Wisconsin - Madison

Kretschmer, Jeanette (MS 2004) Thesis: Durability Testing of Optical Fibers Used in the Hybrid Solar Lighting System, University of Nevada - Reno

Schlegel, G. (MS 2003) Thesis: A TRNSYS Model of a Hybrid Lighting System, University of Wisconsin - Madison

Dye, Dan (MS 2003) Thesis: Infrared Non-Imaging Device for a Full-Spectrum Solar Energy System, University of Nevada - Reno

\subsection{HSL BETA SYSTEM AND SYSTEM PERFORMANCE TARGETS}

After the first budget period, a life-cycle model and performance data from the benchmark system were use to establish three primary targets for this project.

1) $\$ 2,000 / \mathrm{m}^{2}$ - Target installed cost per square meter of collected sunlight based on 6,000 units sold annually.

2) 50,000 lumens $/ \mathrm{m}^{2}$ - Delivered lumens (peak) per square meter of collected sunlight to interior space for 10 meter length of optical fiber.

3) Overall system efficiency - at least $56 \%$ of the available lumens in incident sunlight delivered into interior spaces.

A third generation Beta System comprised of the collector, receiver, tracker and fiber bundle has been developed by the research team. At this writing, Sunlight Direct, LLC is manufacturing and marketing the Hybrid Solar Lighting (HSL) that is shown in Fig. 1. 


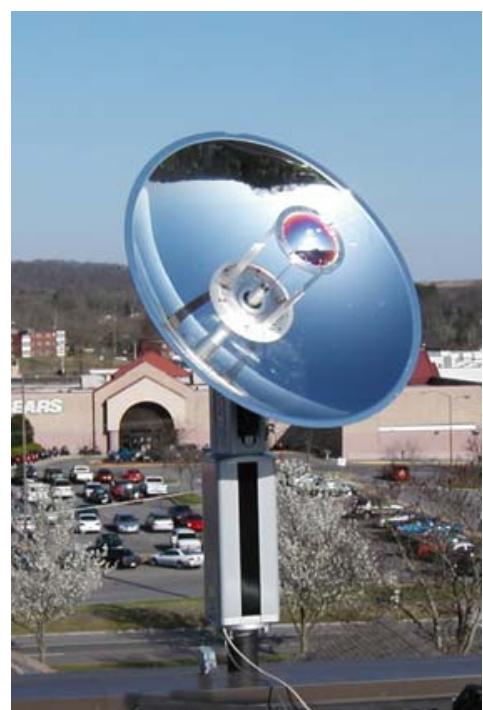

a) Picture of HSL system mounted on roof.

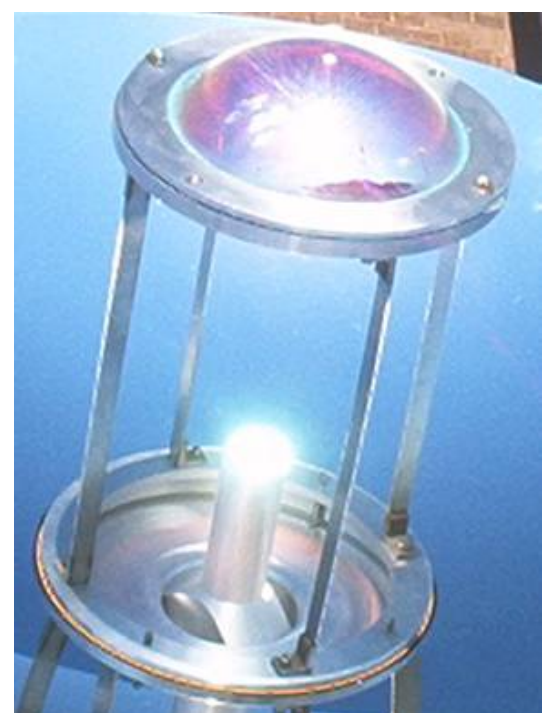

b) Picture of secondary mirror that reflects visible light and passes IR light.

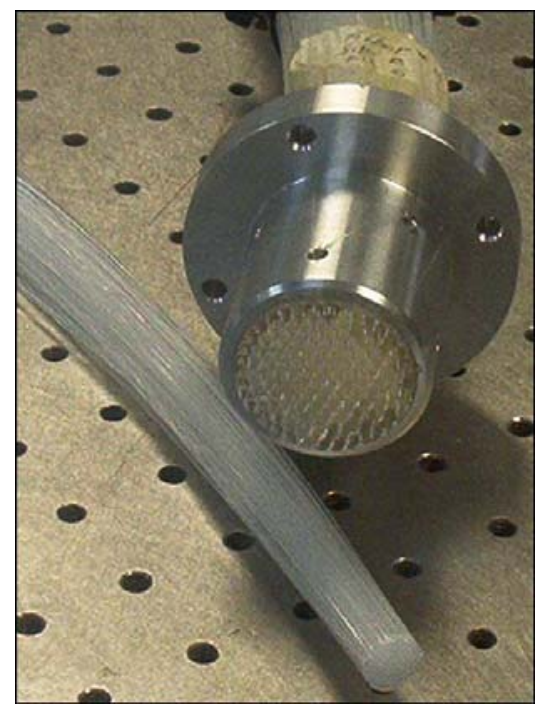

c) Picture of fiber bundle.

Fig. 1 Beta system that is manufactured and marketed by Sunlight Direct, LLC.

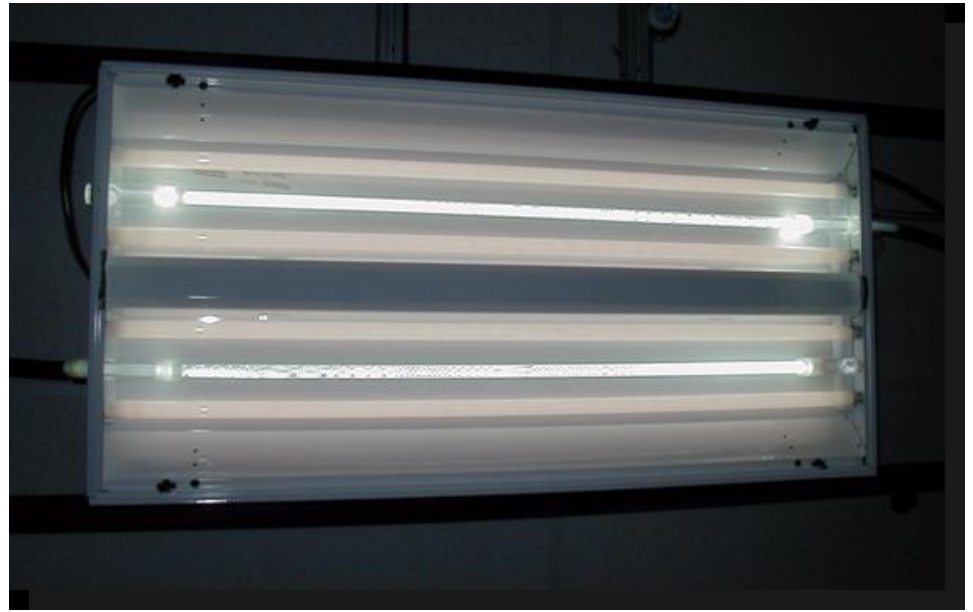

a) assembled unit

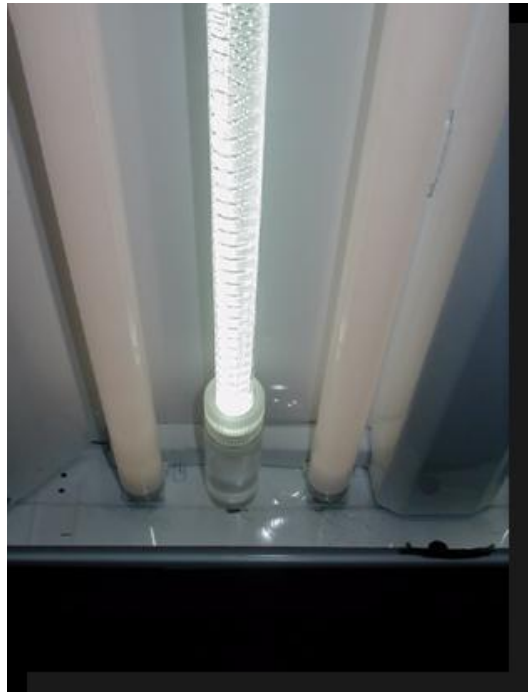

b) Open unit showing sunlight diffusing rod

Fig. 2. Picture of hybrid luminaire

Beta System consists of a one meter diameter aperture parabolic plastic mirror, a Pyrex elliptic secondary mirror, a 1.5 inch diameter fiber bundle with $1263 \mathrm{~mm}$ fibers, and GPS/clock tracker controller. Its physical characteristics are:

- Solar collector height: 60 in.

- Solar collector weight: $120 \mathrm{lbs}$

- Tracking accuracy: 0.1 degree

- Optical fiber length: $30-45 \mathrm{ft}$

- Max. operating wind speed: $50 \mathrm{mph}$ 
- Max. survivable wind speed: $125 \mathrm{mph}$

Its photometric performance characteristics are:

- Peak Delivered Light: 50,000 lumens

- Illumination area: $1,000 \mathrm{ft} 2$ of office space

- Average illuminance: 500-100 lux

- Solar collection efficiency: 50\%

- Color correlated temperature (CCT): $5400 \mathrm{~K}$

- Color rendering index (CRI): 100

A second generation hybrid solar luminaire was developed as shown in Fig. 2.

\section{PATH TO LOW COST HSL SYSTEM FOR BUILDING APPLICATIONS (Contributed by SAIC)}

Although, the HSL system in Fig. 1 comes close to meeting the performance targets set by the research team, the cost of this system will not meet the cost goal. This section presents a path to achieve the cost target.

Sunlight collected on the roof of the building can be transmitted effectively through these optical fibers to the point of use, which can be up to 15 meters from the source. The use of optical fibers to provide daylighting would be cost-prohibitive if the sunlight were transmitted through them at single-sun intensity. However, tests have shown that the fibers can withstand and carry sunlight that is highly concentrated, improving the cost-effectiveness of the approach. An important part of the hybrid lighting system is therefore a solar concentrator that collects and delivers concentrated sunlight onto the ends of the fibers to provide the concentrated light.

Oak Ridge National Lab (ORNL) originated the hybrid lighting concept and has been developing hybrid lighting components and systems for several years. In 2001, with the support of the Department of Energy, the University of Nevada Reno (UNR) began work with ORNL to further develop these systems toward the goal of a cost-effective commercial product. Science Application International Corp. (SAIC), with its expertise and experience with solar concentrator and tracker development for heliostat and solar thermal power applications, was given the task of developing a cost-effective near-term concentrator/tracker system for hybrid lighting.

Environmental, optical, operational, and mechanical requirements guided development. A summary of selected specific requirements is given in Table 1.

\section{System Design Approach}

SAIC approached the task with the goal of minimizing the system cost over its lifetime, including fabrication, installation, operation, and maintenance. The emphasis was on a near-term system that could be produced in quantities of 10 to 100 within the next few years. This approach entailed several assumptions and guidelines: 
- To minimize manufacturing cost, high production volumes are desirable. To quickly develop a lowcost system in low production, existing sources of products in mass-production should be examined. Therefore, off-the-shelf equipment and components would be used as much as possible.

- The concentration ratio of the desired system is high enough that optical sun-trackers would not give the desired tracking accuracy. Sun trackers are also notorious for poor tracking performance in marginal solar conditions such as partly-cloudy days. Finally, microprocessor controllers are very inexpensive and very capable. Therefore, a calculated sun position was chosen, with a microprocessor-based control system.

- Low operating costs require that the systems operate autonomously for months or years at a time with no operator involvement.

- Low installation costs require systems that can be set in place on a roof with minimal site preparation and infrastructure requirements. In particular, structural roof penetrations are to be avoided, and costs for electrical service and other trade-based installation costs should be minimized.

- A larger, lower-quality dish concentrator can deliver the same energy to a fiber bundle as a smaller, more-accurate dish. Dish costs increase with accuracy and size, but are a stronger function of accuracy.

Table 1. Environmental, optical, operational, and mechanical requirements for HSL system.

\begin{tabular}{|l|l|}
\hline Environmental & $\begin{array}{l}\text { Capable of being installed world-wide and surviving outdoor, } \\
\text { desert conditions }\end{array}$ \\
\hline Lifetime & 10 years with less than 10\% performance degradation \\
\hline Fiber Capacity & $\begin{array}{l}80 \text { lumens/sq.mm ( 800 suns) peak, 60 lumens/sq.mm ( 600 } \\
\text { suns) average on fibers }\end{array}$ \\
\hline Delivered Power & $\begin{array}{l}1500 \mathrm{~W} \text { delivered into 5cm diameter at 1000W/sq.m solar } \\
\text { insolation }\end{array}$ \\
\hline Incidence Angle & $<15$ degrees from centerline of fiber \\
\hline Tracking & $\begin{array}{l}\text { Keep image on fibers at all times; 0.1 degree maximum } \\
\text { tracking error }\end{array}$ \\
\hline Mirror area & 1.5 sq.m minimum \\
\hline Autonomy & $\begin{array}{l}\text { Operate without operator intervention except to } \\
\text { enable/disable }\end{array}$ \\
\hline Clock & $\begin{array}{l}\text { Self-synchronize clock within 10 seconds of correct time at } \\
\text { all times }\end{array}$ \\
\hline System Power & $\begin{array}{l}\text { Self-power from PV panel with battery backup; alternatively, } \\
\text { power from external DC supply at 12VDC }\end{array}$ \\
\hline Calibration & Self-calibrate tracking to maximize energy delivered to fibers \\
\hline Automated operation & $\begin{array}{l}\text { Automatically track, stow, and operate, including off-track } \\
\text { and night-time low-power operation }\end{array}$ \\
\hline Mount & Mount to 3 in.OD vertical pipe (standard for satellite dishes) \\
\hline Tracking Speed & 0.5 deg/sec slew, 0.1 deg/sec tracking \\
\hline Interfaces & Switch closure to enable, status display (LED's) on controller \\
\hline
\end{tabular}

\section{Design Analysis}

SolTrace ray-tracing computer code was used to quantify the last bullet of the previous section. The purpose of the study was to investigate the requirements for a dish to deliver $1500 \mathrm{~W}$ of solar power into a 5 -cm diameter receiver under conditions of $1000 \mathrm{~W} / \mathrm{sq} . \mathrm{m}$. insolation. The results were developed in terms 
of the accuracy of the dish, expressed as an RMS slope error of the surface of the dish compared to a perfect parabola. Fig. 3 shows the results of the study, plotted against the diameter of the dish concentrator.

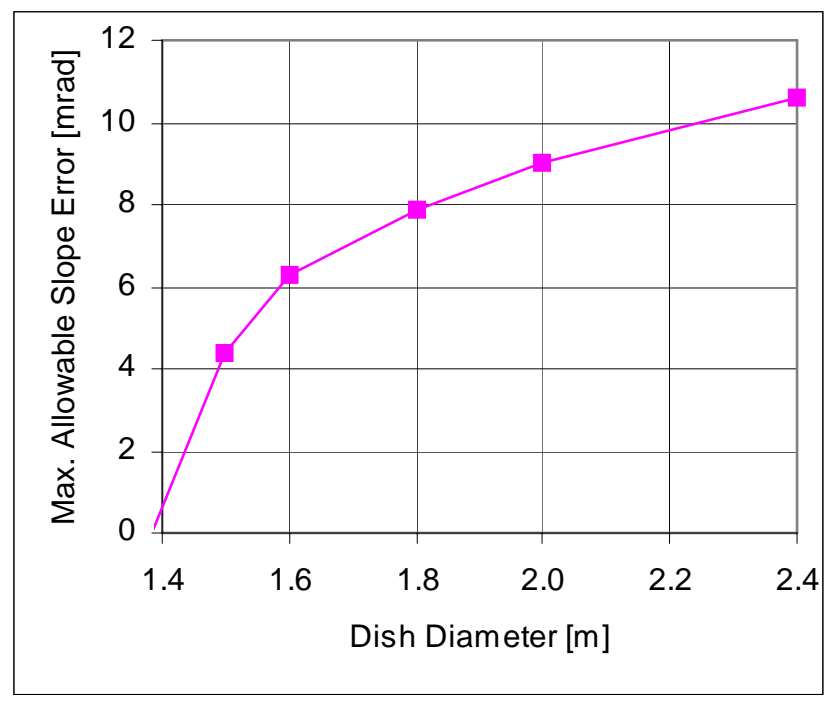

\section{Fig. 3. Maximum Allowable Slope Error to Deliver 1500W of Power to a 5-cm Diameter Receiver}

As the size of the dish increases, the allowable slope error also increases. Whereas a 1.6-m diameter dish could only have $6 \mathrm{mrad}$ of slope error and still deliver the desired power, a 2.0 -m diameter dish could be allowed a slope error of about $9 \mathrm{mrad}$, and a $2.4-\mathrm{m}$ dish could have a RMS slope error of over $10 \mathrm{mrad}$.

These results were used to screen and evaluate potential dish concentrators for use in the hybrid lighting system.

\section{Prototype System Design}

Using the system requirements and design approach assumptions, potential dish concentrators were evaluated. For prototypes, ORNL had used a glass reflector developed for train lights that cost $\$ 2400$ for a 46 in.-diameter $(1.17 \mathrm{~m})$ mirror. Besides the high cost of these mirrors, the glass was heavy and the coating on the surface degraded badly upon exposure to the atmosphere. Other dishes considered included pressure-formed aluminum dishes with vacuum-deposited reflectors and thermo-formed plastic dishes with deposited coatings. Unfortunately, these were not available in mass-production quantities so costs for prototypes were high (e.g., \$300-400 each for 1-1.5m diameter units).

In the spirit of using already mass-produced dish structures, satellite dishes were considered. Spunaluminum dishes did not have adequate surface finishes, so they were eliminated. Fiberglass dishes were considered, but no good contact could be made with a manufacturer to get detailed data. The least-cost dish was a pressed-steel dish from Fortec Industries (model FS6D, www.fortecstar.com), with a retail price of $\$ 135$ (OEM cost around $\$ 50)$ for a $1.8 \mathrm{~m}$-diameter $(6 \mathrm{ft}$ ) dish (e.g., about $\$ 20 /$ sq.m OEM cost). The surface finish of the steel was suitable for application of a reflective film (Reflectech, about \$20/sq.m) after some slight paint texture was removed with light sanding. 
After the dish was sanded and covered with reflective film, lookback testing was performed to measure the optical quality of the dish. The results are shown in Fig. 4, presented as the amount of solar energy that would be reflected by the dish into a given aperture size assuming $1000 \mathrm{~W} / \mathrm{sq} . \mathrm{m}$ insolation and $95 \%$ reflectance. As expected, the dish is of relatively poor quality, and would only reflect about $1200 \mathrm{~W}$ to a target $5 \mathrm{~cm}$ in diameter. However, the low cost of such a dish would make it possible to make up for this by adding a small amount of area to get to a dish that meets the optical requirements cost-effectively.

Using the Fortec satellite dish as a base, the rest of the low-cost dish/tracker system was assembled from off-the-shelf components and systems. A low-cost microprocessor controller used by SAIC in other projects was used to control the system.

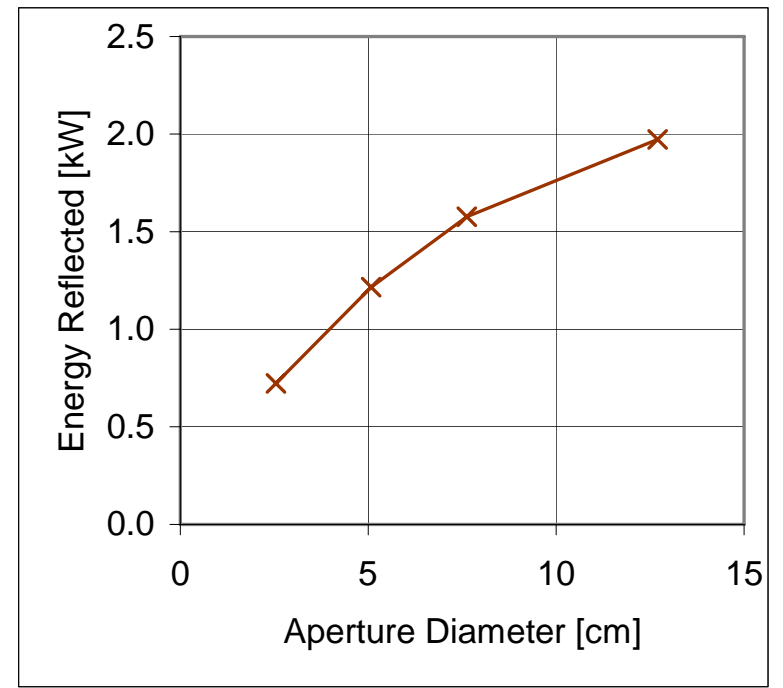

Fig. 4. Optical Quality of Pressed Steel Satellite Dish

Significant components of the final system are listed in Table 2 and discussed in the paragraphs that follow.

Table 2. Major components of low cost HSL system

\begin{tabular}{|l|l|}
\hline Component & Description \\
\hline Controller & Z-World “Little PLC" w/custom input/output interface board \\
\hline Elevation Drive & Satellite dish linear actuator with encoder feedback \\
\hline Azimuth Drive & $\begin{array}{l}\text { 12VDC gearmotor with chain drive to large-diameter turntable and } \\
\text { shaft-mounted optical encoder }\end{array}$ \\
\hline Support Structure & Beam-type flat roof support with platform for turntable \\
\hline Power Supply & $\begin{array}{l}\text { Thermophotovoltaic cells at focus of dish, with charge controller } \\
\text { to battery backup }\end{array}$ \\
\hline Sun Sensor & Low-cost PV cell sensor \\
\hline Clock Synchronization & Automatic, using sun-slit sensor \\
\hline Communication & RS-232, switch closure \\
\hline
\end{tabular}




\section{Controls}

The microprocessor controls all aspects of the system, including communications, tracking, and optimization of power (light) output. The system uses a calculated sun position to avoid problems with off-tracking in marginal solar conditions. The encoder feedbacks from the elevation and azimuth gear trains are used to determine the orientation of the system. The control software includes optimization routines to adjust tracking to maximize the output of the system. The optimization routine also accommodates shifting of the roof, tilt or sag of the dish components, and other factors. The system is designed to operate autonomously after initial installation; the only operator control is a simple switch closure to enable operation.

\section{Tracking System}

The tracking system was designed to meet the mechanical tracking and accuracy requirements at low cost. Wind and gravity loads require high output torques, but tracking speeds need not be high so total power is low. A linear actuator acting on a pivot was selected for the elevation drive. This is a common design for satellite dishes, and is a hard system to beat for low cost and rigidity. The azimuth drive system, with its requirement for nearly 360-degree motion, was more complex. A chain driven by a DC gear motor was selected as the lowest-cost approach to providing the needed torque, rotational range, and accuracy.

\section{Support Structure}

To minimize installation costs, the system was designed with long beams that would distribute the forces from the system over a large mounting area on a flat roof. This eliminated any need for structural roof penetrations. The beams also form a natural platform on which the azimuth turntable was mounted.

\section{Power Supply}

The conventional approach to providing power to equipment located on a roof involves having licensed electricians running conduit and pulling wiring to each unit. This is cost-effective for HVAC equipment that requires large amounts of power. However, the power needs for these small tracking systems are extremely low, leading to the conclusion that a self-powered system would be cost-effective. The savings in trade labor to install wiring pays for a small PV array and batteries on each unit to make them autonomously powered. This has the added advantage of making the systems immune to power outages in case of a blackout, the daylighting systems would continue to deliver light to the interior of the building. In the original design, a thermophotovoltaic (TPV) array was located just behind the "cold mirror" that reflected the visible light to the fibers. The output of the TPV array was calculated to be enough to power the system. In practice, the cost of the TPV array was such that a simple flat-plate PV panel was later selected to supply power to the system.

\section{Sun Sensors and Clock Synchronization}

The tracking optimization routine relies on maximizing the delivery of light to the fiber optics. A sensor was designed for detecting the light input to the fibers, but a sun sensor is also needed to calibrate the analysis. The controller must be able to distinguish when a change in light input to the fibers is due to 
tracking changes or simply a cloud or other outside influence on the insolation. A simple PV-based sensor, mounted on the dish so it tracks with the system, provides this function.

An additional sensor was developed and tested in this prototype for synchronization of the system clock. This unique sensor had a vertical slit through which the sun could shine onto a small sensor. The slit was oriented to the South, so that the sensor would measure a signal during the sun passage across the slit each day. Knowing the orientation of the slit, the time of the sun passage could be calculated by the controller and the signal could be processed to generate a clock update each day of operation. In this way, the system clock could be kept accurate over long periods. Initial orientation is measured when the system is first installed and the clock is synchronized by the operator.

\section{Prototype System Cost Analysis}

The costs of all components of the prototype system were recorded and tracked. For the prototype system, the cost of components was just over $\$ 1,300$, or just about $\$ 520 /$ sq.m. For information purposes, Fig. 5 is a pie chart showing a breakdown of the costs.

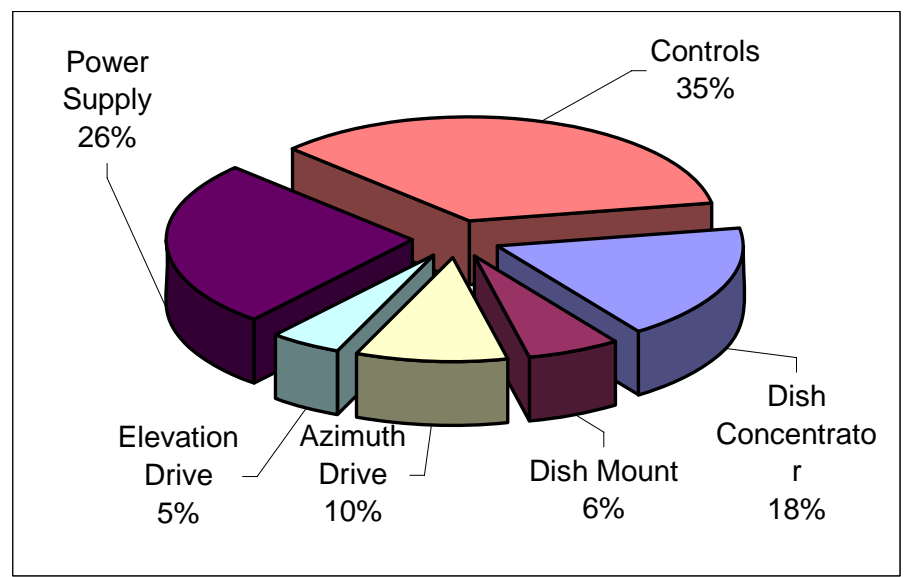

Fig. 5. Breakdown of Costs of Prototype Dish/Tracker System

The costs for controls and power supply are the largest portion of the prototype cost. The controls costs were high because no quantity prices were obtained. The cost for the PV panel was estimated at $\$ 200$, and the charge controller was $\$ 100$. In any quantity production, costs for these and other components could be expected to decrease significantly. For instance the charge controller could be incorporated into the control interface board, which would be implemented as a simple printed circuit board. Finally, the dish cost was based on a single-unit purchase price of $\$ 134$, not the OEM price of about $\$ 50$.

\section{System Operation}

After the prototype system shown in Fig. 6 was assembled, it was operated for testing over a period of several days to ensure proper operation of all the components. During this time, the original thermophotovoltaic receiver did not deliver expected power output, so long-term autonomous testing was not possible. However, the system demonstrated automated tracking and all normal functions of the system were verified. 


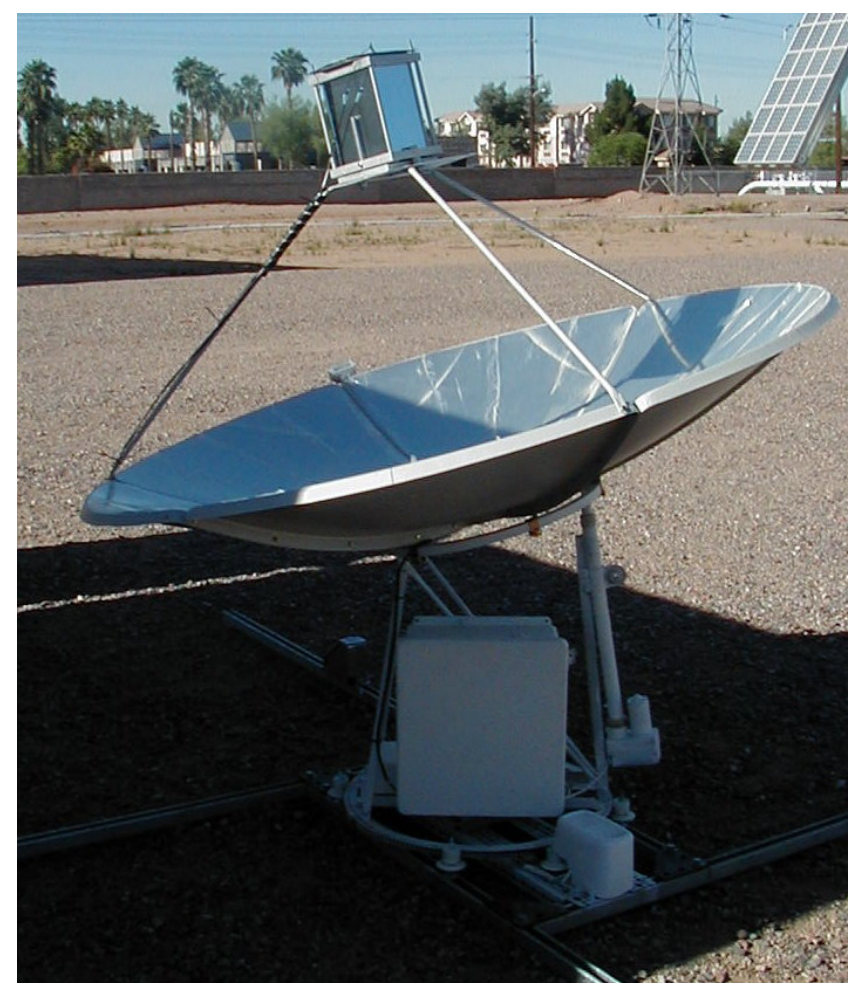

Fig. 6. . Prototype low-cost dish/tracker system based on a commercially-available satellite dish reflector and simple, low-cost tracker components. The single-unit cost of the prototype system was about $\$ 1300$ (\$520/sq.m), with potential for significant additional reductions in quantity production. This prototype demonstrates the potential to develop a cost-effective dish/tracker system that ensures economic feasibility of this system.

\section{Conclusions}

This task has demonstrated that a low-cost concentrator/tracker system can be assembled from commercially available components to form a near-term dish/tracker for hybrid lighting systems. Presumably, a system developed specifically for this application can provide further cost reductions and performance enhancements that will contribute to the cost-effective implementation of this technology. 


\section{PHOTOBIOREACTOR DEVELOPMENT PROGRESS (Contributed by Ohio)}

It is generally believed that a portfolio of options will be needed to address the complexities of greenhouse gas emission control. Engineered photosynthetic systems offer advantages as a viable near-tointermediate term solution for reduced carbon emissions in the industrial and energy sectors. Such systems could minimize capital and operating costs, complexity, and energy required to transport $\mathrm{CO}_{2}$ that challenge sequestration for smaller fossil units. The potential for low-cost control could be critical for smaller units, where capital cost per megawatt could be substantial for $\mathrm{CO}_{2}$ control. For coal to remain competitive, especially in the rapidly emerging distributed generation market and to ensure future fuel diversification, low cost marginal control systems, such as photosynthetic systems, must be developed.

Despite the large body of research in the area of photosynthesis for carbon sequestration, little work has been done to create a practical system, one that could be used with both new and existing fossil generating units. For example, use of raceway cultivators ignores land availability limitations at many existing fossil generation plants. Few existing smaller generation units could find $1000+$ acres of suitable land for siting and constructing a microbial pond. Additionally, how would the $\mathrm{CO}_{2}$ be introduced to the photosynthetic agents? Would such a system need expensively separated $\mathrm{CO}_{2}$ (not direct flue gas) for sparging, thus vastly increasing the system cost? Would local stack emissions restriction prevent dispersion of flue gas at ground level?

In addition, questions exist about supply and distribution of light. For example, in a pond, only organisms near the surface would receive sufficient photons for photosynthesis due to the high degree of reflection and attenuation caused by the water. If organisms had to exist at the surface (and outside), would cold weather have a negative impact on their performance? Further, to keep any such system operating at maximum carbon uptake rate, mature and dead organisms would need to be harvested. How would that be accomplished and at what rate? Finally, although numerous post-harvesting uses exist, what would be the optimal use with respect to the specific application and host site? These questions - questions directly related to application of such a unit at any practical installation - must be addressed before deploying a practical photosynthetic system.

The concept behind engineered photosynthesis systems is straightforward. Even though $\mathrm{CO}_{2}$ is a fairly stable molecule, it is the basis for the formation of complex sugars (food) by green plants through photosynthesis. The relatively high content of $\mathrm{CO}_{2}$ in flue gas (approximately $14 \%$ compared to the 360 ppm in ambient air) has been shown to significantly increase growth rates of certain species of microalgae. Therefore, application is ideal for contained systems, engineered to use specially selected (but currently existing) strains of microalgae to maximize $\mathrm{CO}_{2}$ conversion to biomass, absorbing greenhouse gases (Brock, 1978; Ohtaguchi et al., 1997). In this case, the microalgal biomass is the carbon sink.

For example, let's say the composition of "typical" microalgae (normalized with respect to carbon) is $\mathrm{CH}_{1.8} \mathrm{~N}_{0.17} \mathrm{O}_{0.56}$, then one mole of $\mathrm{CO}_{2}$ is required for the growth of one mole of microalgae. Based on the relative molar weights, the carbon from $1 \mathrm{~kg}$ of $\mathrm{CO}_{2}$ could produce increased microalgal mass of 25/44 $\mathrm{kg}$, with $32 / 44 \mathrm{~kg}$ of $\mathrm{O}_{2}$ released in the process, assuming $\mathrm{O}_{2}$ is released in a one-to-one molar ratio with absorption of $\mathrm{CO}_{2}$. Therefore, a photosynthetic system provides critical oxygen renewal along with the recycling of carbon into potentially beneficial biomass.

Enhanced natural sinks could provide an economically competitive and environmentally safe carbon management option because they do not require pure $\mathrm{CO}_{2}$ and they do not incur the costs of separation, capture, and compression of $\mathrm{CO}_{2}$ gas (Kajiwara et al., 1997; Hirata, et al., 1996a). Among the options for 
enhanced natural sinks, the use of existing organisms in an optimal way in an engineered photosynthesis system is lower risk, lower cost, and benign to the environment. This contrasts the use of ocean-based sinks, which could present problems (Bacastow and Dewey, 1996). Large amounts of iron must be added to the ocean to promote additional $\mathrm{CO}_{2}$ fixation. As a result, there may be little control over resulting growth. "Weed" plankton, the most likely organisms to grow, would not provide sufficient nutrients for the food webs, generating a high probability of negative environmental impact (Cooksey et al., 1995).

An engineered photosynthesis system could be placed at the source of the emissions to allow measurement and verification of the system effects, rather than being far removed from the emissions source, as is the case with forest-based and ocean-based natural sinks. The power source is natural and abundant. And the energy is converted to byproducts - biomass- that could be used as a fuel, fertilizer, feedstock, or source of hydrogen (Fisher, 1961). And even though some carbon is eventually released from biomass through decomposition, bioconversion is the fastest and safest method to add carbon to natural terrestrial sinks.

Further, the process described in this paper also requires relatively small amounts of space, estimated to be $1 / 10^{\text {th }}$ of a comparable raceway cultivator design. Because the organisms are grown on membrane substrates arranged much like plates in an electrostatic precipitator, there is little pressure drop. The system described here could be used at virtually any power plant with the incorporation of translating slug flow technology to create favorable conditions, such as reduced temperatures and enhanced soluble carbon concentration. Finally, engineered photosynthesis systems will likely benefit from current research into enhancing the process of photosynthesis, either genetically or via photocatalytic reactions.

The conceptualized process introduced by Ohio University (Ohio), shown in Fig. 7, begins after the flue gas has passed through suitable particulate control device(s) so that the gas will be substantially free of solid impurities. The flue gas passes through the bioreactor, which houses vertically suspended growth membranes growing thermophilic organisms, arranged to minimize pressure drop of the flue gas throughout the reactor. The growth substrate, which is a woven fibrous membrane, must be resistant to wear in the harsh environment of the flue gas and corrosive potential of the growth media and, because of the vertical position, offer a high degree of adhesion with the microalgae. However, the degree of adhesion can be too high, becoming problematic for harvesting.

\section{Growth Media Transport System}

The growth media transport system developed by Ohio consists of two distinct parts - a circulating fluid system and liquid distribution system. The circulating fluid system is a closed looped, pump and gravity fed transmission system where water containing defined levels of nutrients and soluble carbon (or void of soluble carbon) is delivered to the membrane support for the organisms. The water then flows through distribution headers and then into the fibers by gravity assisted capillary action. A view of the capillary transport of water on a populated substrate is seen in Fig. 8.

One of the more significant engineering challenges of this project is nutrient enhancement and delivery to the photobioreactor. Microalgae often more easily fix carbon and inorganic nitrogen in soluble form. Translating slug flow technology, developed at Ohio University's Institute for Corrosion and Multiphase Processes, not only increases concentrations of nutrients in the aqueous phase by directly removing them from the flue gas, but also lowers flue gas temperatures (Jepson, et al., 1993). Slugs create zones of greatly enhanced gas-liquid mass transfer, putting $\mathrm{CO}_{2}$ and $\mathrm{NO}_{\mathrm{x}}$ into soluble form for the microalgae. Such transfer would greatly speed up the natural process of photosynthesis, which in large-scale bioreactors, may be limited by the rate of diffusion of the carbon through the organism membranes. 


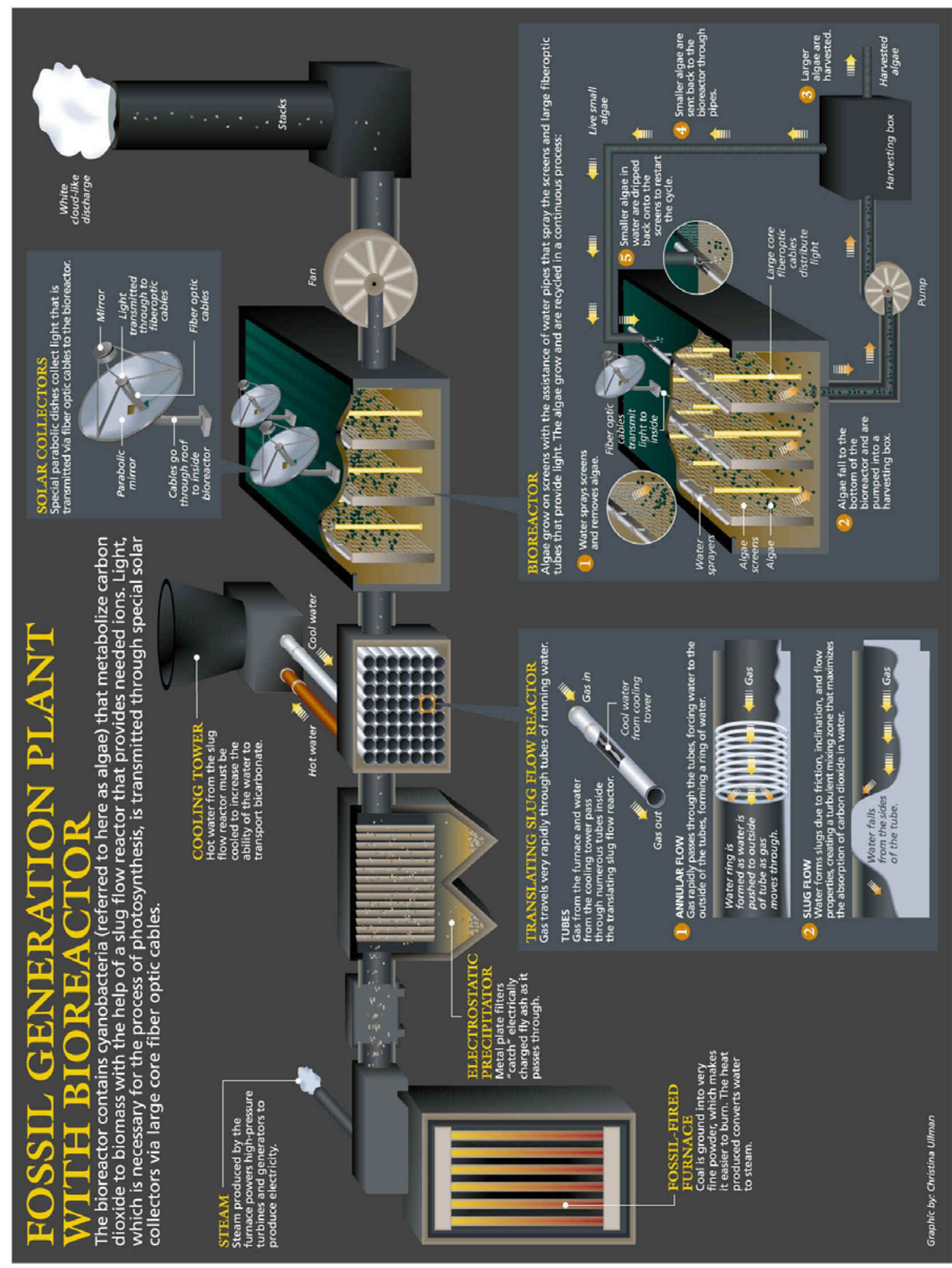

Fig. 7. Solar bioreactor concept for $\mathrm{CO} 2$ sequestration using microalgae growing in vertical biofilms 


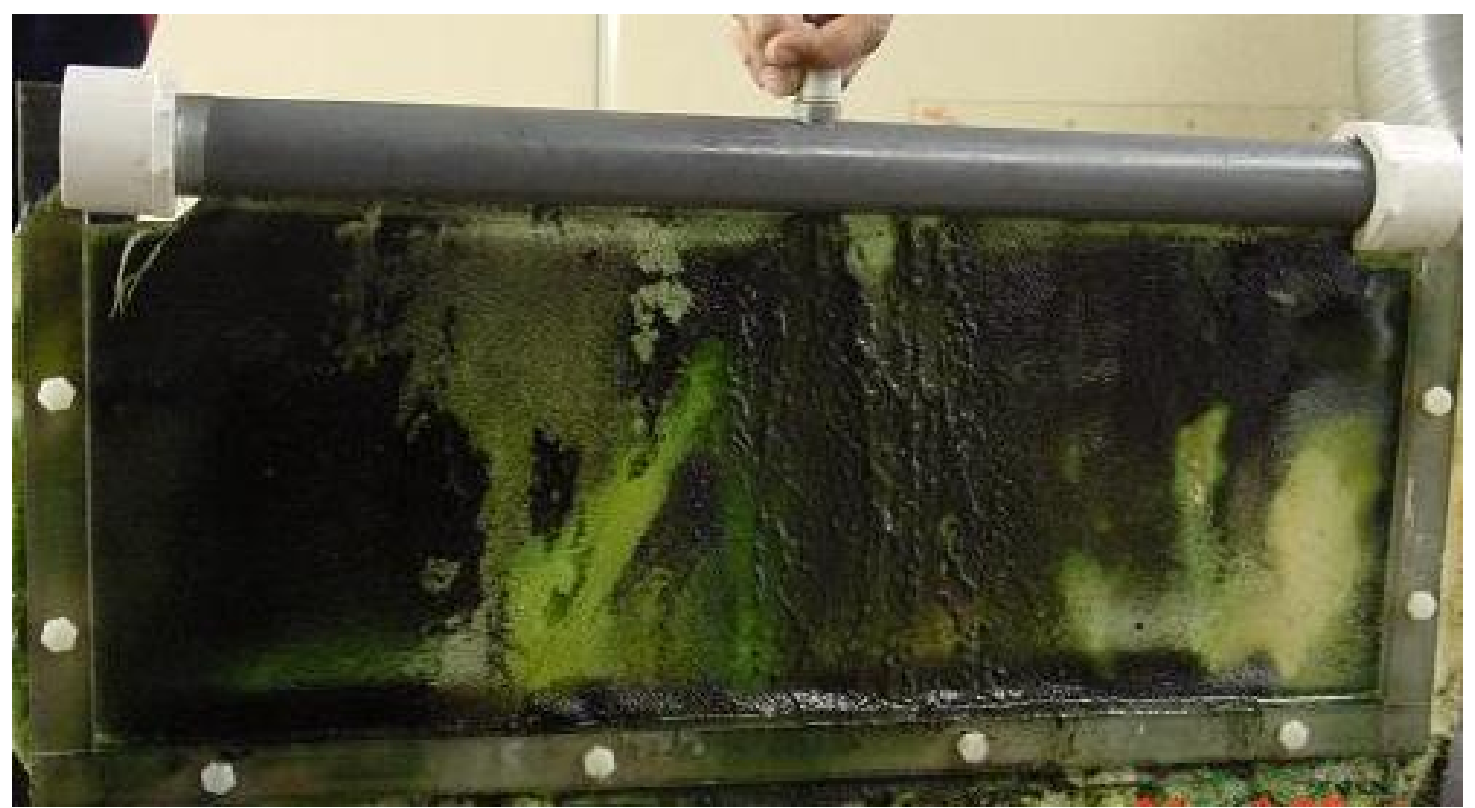

Fig. 8. Populated substrates showing capillary transport of water

\section{Photon Collection and Delivery}

Solar photons are the energy source of the system and one of the primary factors determining system efficiency. In order to utilize solar photons at maximum efficiency, the light delivery subsystem must deliver a sufficient quantity and quality of photosynthetic photons deep within the bioreactor and minimize the light loss due to reflection and adsorption. Direct, filtered sunlight is collected and delivered into the bioreactor, via collection optics and large-core optical fibers. As seen in Fig. 7, the collector will mount outside the bioreactor, preferably on top of the reactor. The actual installed collector for the pilotscale reactor is shown in Fig. 9.

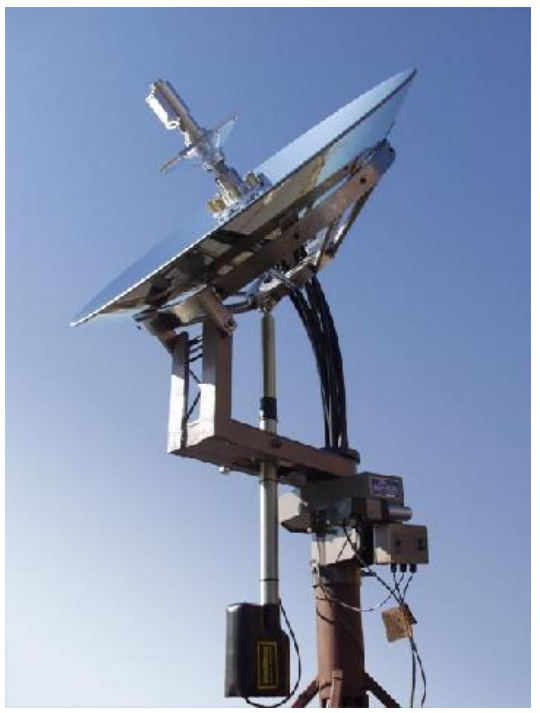

a) Benchmark system

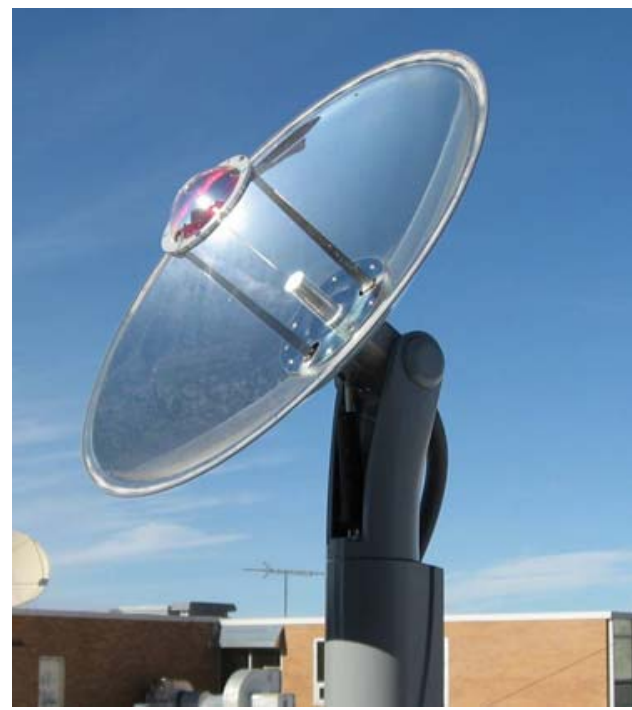

b) Beta system Fig. 9. Solar Collector Mounted Above Pilot-Scale Bioreactor 
The visible light from the sun reflected from collector dish and secondary optics is launched into an array of optical fibers. These large core fiber optic cables then supply photons necessary to support photosynthesis, using special distributors located between the vertical growth membranes (Fig. 10).

By controlling attenuation through the fiber optic cables and using specially designed distributor plates made from similar materials, a uniform distribution of photons may be supplied, typically at a rate between $60-120 \mu$ mols $\mathrm{m}^{-2} \mathrm{~s}^{-1}$. This distribution is a key element in reactor design. The sunlight, originally collected by tracking mirrors (optimizing solar collection) will provide over $2000 \mu \mathrm{mols} \mathrm{m}^{-2} \mathrm{~s}^{-1}$ of suitable photons throughout the day. However, at that rate, most photons would be wasted, as photosynthesis in thermophiles occurs at much lower levels of light.

A further point of interest is that sunlight contains wide spectra of energy; some is useless to the photosynthetic organisms, such as infrared, and some is harmful, such as certain ultraviolet spectra. Filters remove unwanted portions of the solar spectra and allow it to be used for thermal photovoltaic production of electricity needed to power the auxiliary components of the system.

\section{Organism Harvesting and Repopulation}

The harvesting system provides a way to remove mature organisms, or reduce cell density to promote further cell division, as well as repopulate the membranes with developing organisms, thus maximizing carbon uptake. Preliminary tests indicate that microalgae, removed in "clumps" from the growth strata, are easily agitated into a diffuse state. Mature microalgae (organisms with a low potential for carbon utilization) can be removed and microalgae that are maturing, (organisms with a high potential for carbon utilization), can be repopulated on the growth strata.

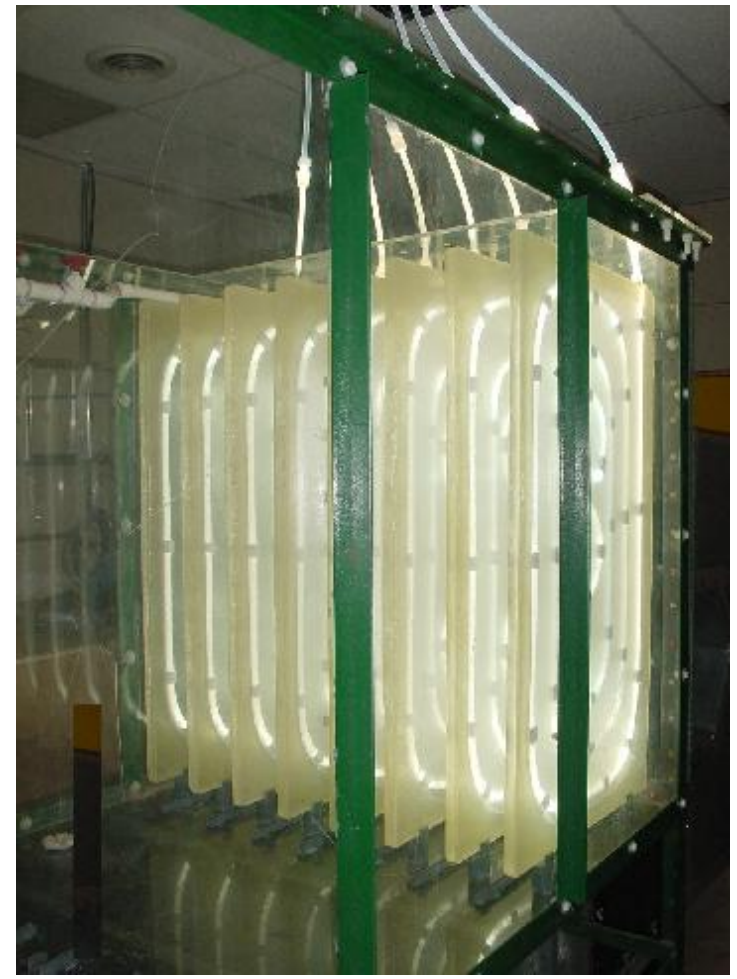

a) Alpha light sheet

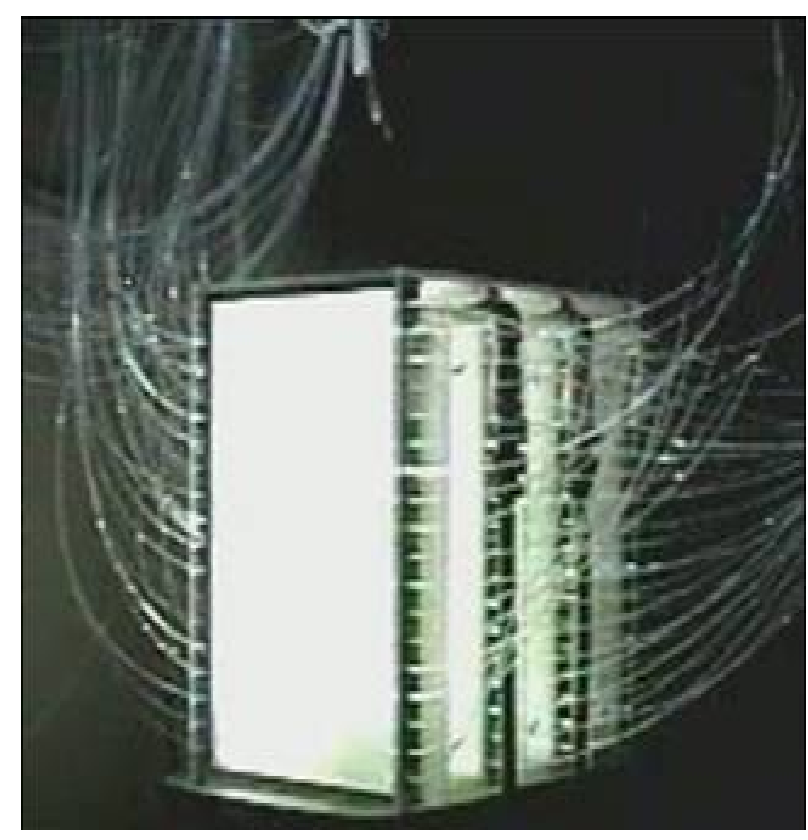

b) Beta light sheet

Fig. 10. Lighting panels with fiber optic leads 
The harvesting for Ohio's experimental bioreactor is done using the water distribution system to minimize needs for additional components. By increasing the water pressure to the distribution header, a great flow of water per unit area of membrane is achieved, creating a gentile washing effect. This gentle washing is critical, so as not to shock the organisms and delay continued growth. Further, the gentle washing process is generally $30-40 \%$ effective (on a mass basis) in removing organisms from the membrane substrate, which is needed to maintain cell density to sustain continued cell division. Illustrations of the membranes before and after washing are shown in Figures 11 and 12.

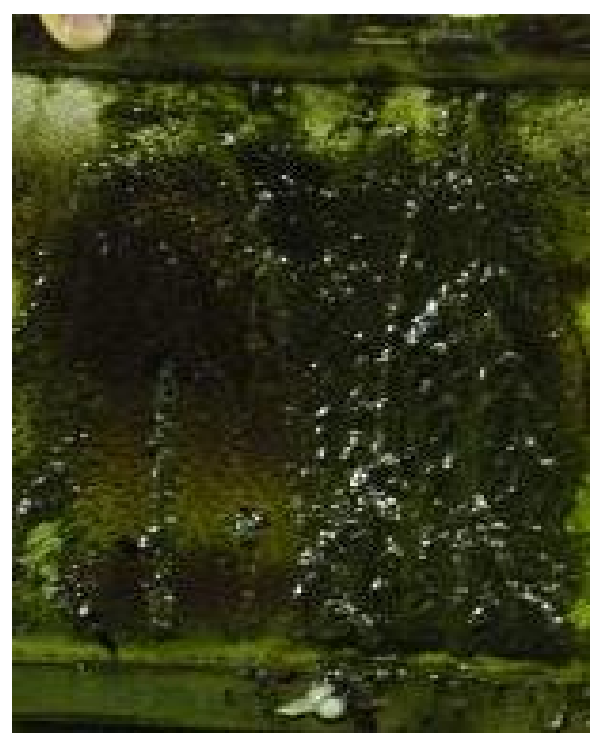

Fig. 11. Membrane populated with microalgae

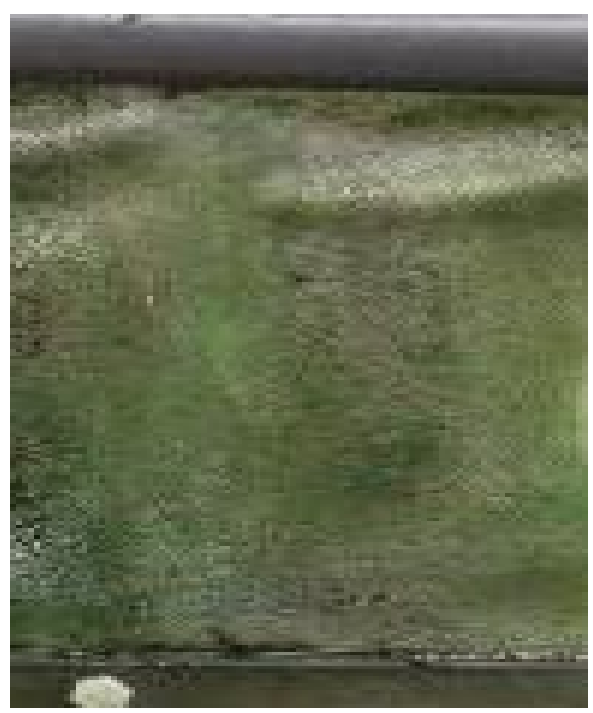

Fig. 12. Membrane washed with the harvesting system

\begin{abstract}
Algal Productivity
Sustainability tests with approximately 30 gallons of algae and two Omnisil membranes were performed to quantify the growth of algae in the bioreactor. We have completed the initial mass determination procedure, which enabled us to quantify the algae growth over the course of the experiment. The daily yield of organism was determined, after harvesting each night and is shown in Fig. 13. Also shown in Fig. 13 is the average (daily) solar flux for Athens Ohio during the experiment as measured at Scalia Laboratory, Ohio University's weather station.
\end{abstract}

We noted that the productivity for the following day tracked the average solar flux for the previous day's growth very well (correlating to over 98\%). However, it seems intuitive that if the solar collector/distributor system is tuned to produce an optimal photon flux $\left(100-200 \mu \mathrm{molm}^{-2} \mathrm{~s}^{-1}\right)$ that reducing the daily photon exposure would correspondingly reduce biomass productivity.

The tests were repeated for algal growth in the bioreactor over a period of 10 days following an acclimation period of seven days. The results, shown in Fig. 14, were slightly lower than the results presented in Fig. 13, especially when normalized to the average solar flux from the day before. This is likely because the solar collector experienced significant loss of reflective coating between May and July. However, these results are significant because they show the cyanobacteria have a considerable ability to grow once acclimated to the membrane substrate. 


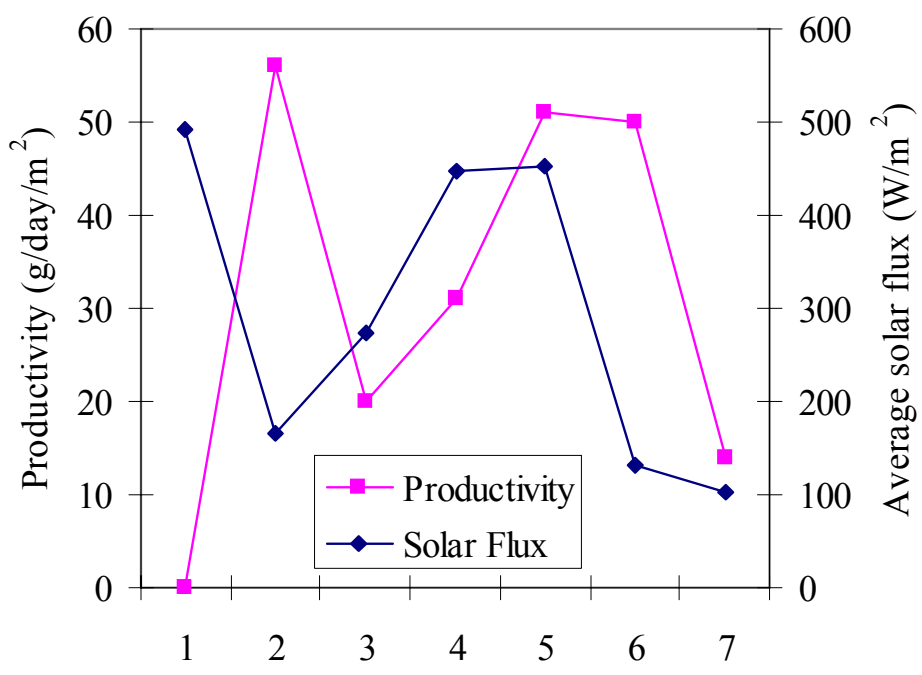

Fig. 13. Preliminary Productivity Data

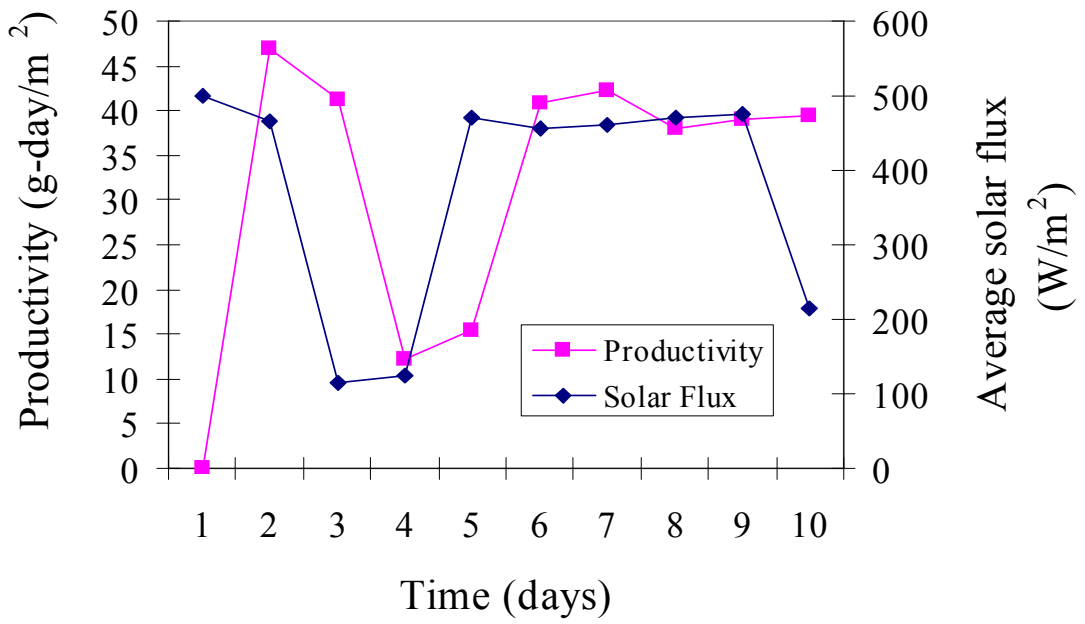

Fig. 14. Repeated Productivity Results

\section{Expected Cost of Deployment}

For discussion purposes, assume a power plant has a gross capacity of $200 \mathrm{MW}$, a capacity factor of $65 \%$ operating as a load-following unit (peaking during the day when solar photons are available), with a heat rate of $9000 \mathrm{BTU} / \mathrm{kW}-\mathrm{hr}$, burning a coal containing $70 \%$ carbon by mass and a higher heating value (HHV) of $12,000 \mathrm{BTU} / \mathrm{lbm}$. The bioreactor for this economic case study is assumed to remove $50 \%$ of all $\mathrm{CO}_{2}$ during daylight hours (during peak $\mathrm{CO}_{2}$ production), and the incident photon flux on the solar

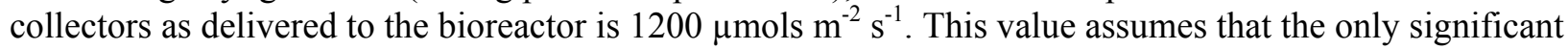
decrease in photon flux is not solar angle (overcome by mirror positioning), but cloud cover.

Note that the key cost parameter is the cost of the solar collectors. It is estimated that the collectors, built by hand, would cost $\$ 30,000$ each to install. (This was about the cost of the Benchmark system.) Without mass production and economies of scale, $\$ 30,000$ per collector would translate to $\$ 2,000$ per ton of $\mathrm{CO}_{2}$ 
removed from the flue gas. However, commercialization and mass manufacture of the solar collector technology is likely. The cost target established by the research team is $\$ 2,000 / \mathrm{m}^{2}$ for use as a lighting system in commercial buildings.

To examine the effect of photon conversion efficiency at a collector cost of $\$ 2,000 / \mathrm{m}^{2}$, Fig. 15 was generated. Using the previously stated assumptions, the minimum cost for collection of one ton of $\mathrm{CO}_{2}$ over the lifetime of the bioreactor, assuming continuous use, would be $\$ 80$. Assuming $30 \%$ conversion efficiency, the more likely cost is $\$ 240$ per ton - with no revenue generated from the resulting biomass.

However, if mass production were to occur, it is conceivable that solar system could be reduced to $\$ 400 / \mathrm{m}^{2}$ of light collecting area. In that case (labeled as "proposed design"), the economics are very favorable (\$48 per tons) if one assumes 30\% conversion.

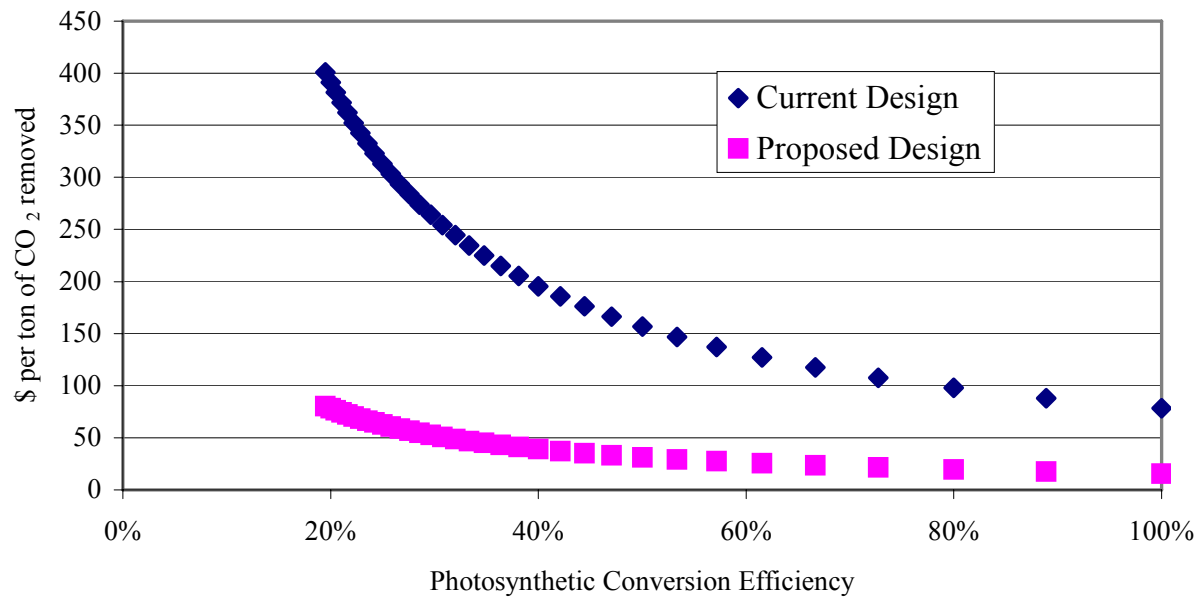

Fig. 15. Cost of one ton of $\mathrm{CO}_{2}$ removed as a function of photon conversion efficiency

If photon attenuation is reduced and deployment of such a unit occurs in a "sunnier" location, the incident

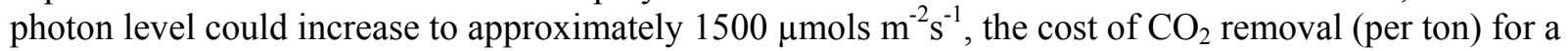
conversion efficiency of $30 \%$ would become $\$ 39$.

\section{Conclusions}

The subsystem research has progressed to the point that a viable pilot-scale bioreactor is being constructed to test long term, sustainable and continuous conversion of $\mathrm{CO}_{2}$ to biomass using collected solar photons. Further, this photobioreactor offers numerous possibilities for not only greenhouse gas mitigation, but also to control a wide variety of pollutants, notably NOx and ammonia slip, while producing a product that could have sustainable economic value.

Further, the productivity data strongly indicate that the harvesting method of higher water flow does not physically stress the algal mass that remains on the substrate. That is critical for long-term sustainability.

Finally, it is clear that the economics of implementation are a significant hurdle to commercialization. Particularly, the cost of the solar collectors and photo distribution systems will be key to providing lowcost greenhouse gas emission remediation. 


\section{CYANOBACTERIAL SPECIES FOR CO2 MITIGATION (Contributed by UA)}

The long-term goal of this task was to investigate the potential of Hybrid Solar Lighting (HSL) in photobioreactor biomass production systems, especially in $\mathrm{CO}_{2}$-mitigation systems. The specific objectives of the current study were: (1) to select cyanobacterial species for $\mathrm{CO}_{2}$-mitigation; and (2) to demonstrate a bench-top lab-scale photobioreactor for growing cyanobacteria for $\mathrm{CO}_{2}$ fixation.

\section{Materials and Methods}

\section{Species and Media}

One mesophilic species and one thermophilic species of cyanobacteria were selected after testing several species. The mesophilic species was Chlorella vulgaris (UTEX 259), obtained from the Culture Collection of Algae at the University of Texas at Austin (UTEX), while the thermophilic species was a pure culture of an unidentified cyanobacterial strain, 1.2. S.C.(2) or simply SC2, originally isolated from Yellowstone National Park by Dr. Keith Cooksey of Montana State University (Fig.16). Proteose medium, a standard medium for Chlorella vulgaris (UTEX 259), was used to culture the former and BG11 was used to culture SC2.
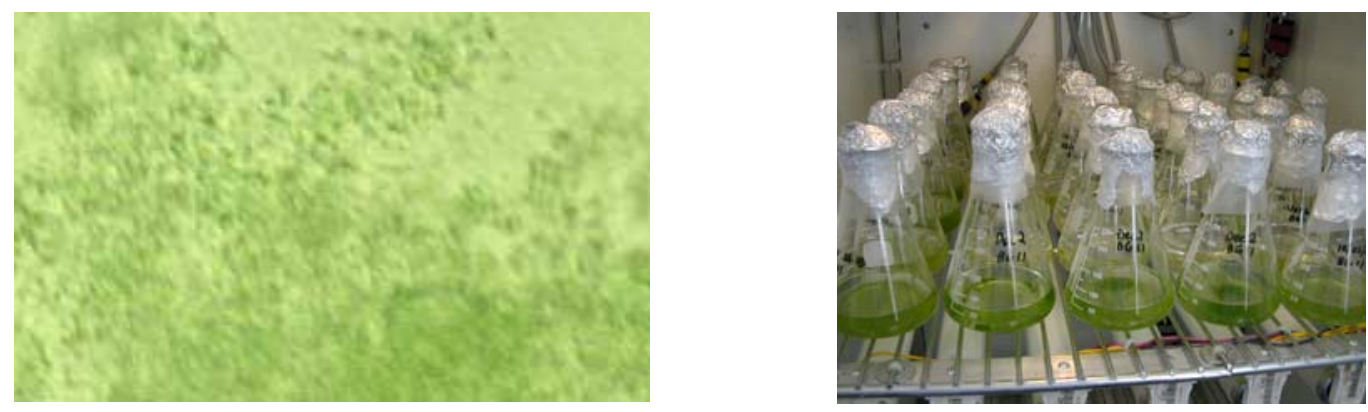

Fig. 16. A micrograph of SC2 (left) and SC2 maintained in flask cultures (right).

Cultures were illuminated with 40-W, 1.22-m (or 48-in)-long fluorescent lamps at a daily photoperiod of $16 \mathrm{~h}$. For $\mathrm{CO}_{2}$ condition, either room ambient $\mathrm{CO}_{2}$ or elevated $\mathrm{CO}_{2}$ concentration was used depending on the experiment. The average room ambient $\mathrm{CO}_{2}$ concentration over 24 hours was within the range of 370 - $405 \mathrm{ppm}$ ( $\mathrm{mol} / \mathrm{mol}$ ). For the elevated $\mathrm{CO}_{2}$ condition, pre-configured $5 \% \mathrm{CO}_{2}$ was used, supplied to the batch culture in a Pyrex flask via $1 / 8$ OD tubing. The $\mathrm{CO}_{2}$ concentration in ppm level was measured using an IRGA, LCA-4 (Analytical Development Company Limited, Hertfordshire, England). Percentage level of $\mathrm{CO}_{2}$ concentration was measured using a NOVA Model 302WP (NOVA analytical systems Inc., NY).

\section{Results Summary}

\section{Mesophilic Species}

The growth characteristics of Chlorella vulgaris (UTEX 259) at 25,35 and $50{ }^{\circ} \mathrm{C}$ in ambient $\mathrm{CO}_{2}$ condition were examined. Each constant-temperature treatment was achieved using a heated water bath (MW-1130A-1, Blue M, Blue island, IL, USA) (Fig. 17). The inoculation was conducted under aseptic conditions under a laminar flow hood to avoid contamination. Fifteen $\mathrm{ml}$ of algae inoculum was used for each sample, and each sample had a total volume of $50 \mathrm{ml}$. The initial biomass used for inoculation was measured non-destructively via optical density. 


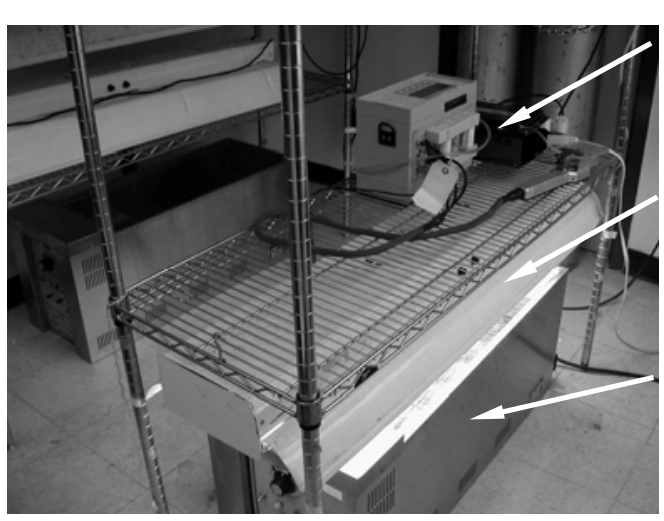

Infra-red gas analyzer (LCA-4, ADC)

Fluorescent lamps

40 WATT CWF x 4

Fig. 17. Apparatus for the heated water-bath experiment

The change in biomass over time was monitored using both measurements of optical density and dry weight. For optical density, absorbance at three fixed wavelengths, 438, 540 and $678 \mathrm{~nm}$, were scanned using a Beckman DU640 spectrophotometer (Beckman Instruments, Inc., Fullerton, CA). Four-week long experiments were conducted. Two different light intensities, $212.2 \pm 7.0$ (S.E.) $\mathrm{mol} \mathrm{m}^{-2} \mathrm{~s}^{-1}$ and $102.5 \pm$ 1.8 (S.E.) $\mathrm{mol} \mathrm{m}^{-2} \mathrm{~s}^{-1}$, were used, representing high and low light conditions, respectively. Each biomass sample was oven-dried for 24 hours at $105^{\circ} \mathrm{C}$ in accordance with standard cyanobacteria sampling (Greenberg et al., 1980). Prior to the oven-drying process, the sample was either centrifuged or filtered to separate the biomass from dissolved nutrients. Samples of Chlorella vulgaris were centrifuged using Eppendorf 5810R (Eppendorf AG, Hamburg, Germany).
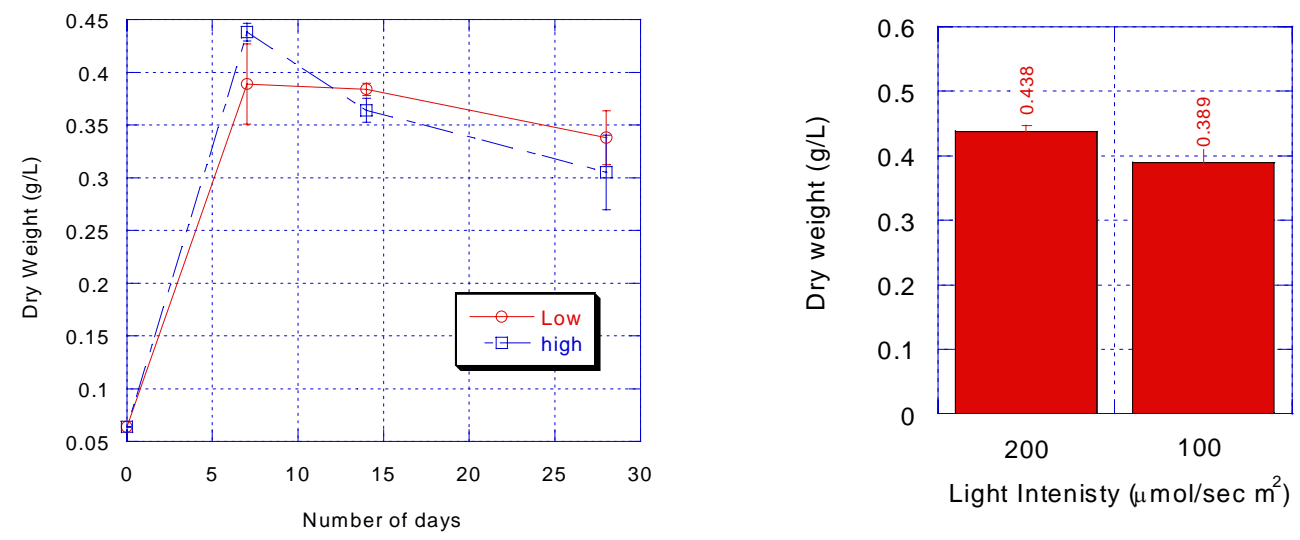

Fig. 18. Time course of dry weight changes of Chlorella vulgaris under two light conditions, ambient $\mathrm{CO} 2$ and $25^{\circ} \mathrm{C}$ temperature (left), and comparison of the final dry weight data between the two light conditions (right). The experiments were repeated twice. The error bars show standard errors, and there was no statistical significance between the two light conditions at $95 \%$ confidence level.

The thermal adaptability of Chlorella vulgaris (UTEX 259) used in this study turned out to be limited. The strain failed to survive at the elevated temperature of $50^{\circ} \mathrm{C}$ ), and also showed limited growth at 35 ${ }^{\circ} \mathrm{C}$. Chlorella vulgaris, however, grew reasonably well at $25^{\circ} \mathrm{C}$ under both high and low light conditions. 
After day 7, the dry weight began to plateau (Fig. 18). The maximum dry weights for high and low light conditions were $0.438 \mathrm{~g} / 1$ and $0.389 \mathrm{~g} / 1$, respectively (Fig. 18). The initial inoculum concentration was $0.064 \mathrm{~g} / 1$ for both light conditions. The resulting specific growth rates $(\mu)$ were 0.228 and 0.231 day $^{-1}$ for the high and low light conditions, respectively, and the doubling time $\left(\mathrm{T}_{\mathrm{d}}\right)$ was 3 days for both lighting conditions. Significant difference in dry biomass did not exist between two conditions.

\section{Thermophilic Species}

Growth characteristics of the thermophilic species SC2 at elevated temperature $\left(50^{\circ} \mathrm{C}\right)$ and elevated $\mathrm{CO}_{2}$ $(5 \% \mathrm{v} / \mathrm{v})$ were examined. The high- $\mathrm{CO}_{2}$ air was made to pass trough a filter and a humidifier filled with autoclaved nano-pure water into 250-mL Pyrex flasks wherein the cultures were grown (Fig. 19).

Incoming flow was measured using a flow meter.

Stationary phase (Long-term) experiments: The aim of this experiment was to investigate the stationary phase (plateau) of the growth curve. A light intensity of $250 \mathrm{~mol} / \mathrm{sec} \mathrm{m}^{2}$, which was the highest light intensity attainable for the experimental system, was employed for this experiment. The flow rate was 0.0021 gas $1^{-1}$ medium $\mathrm{min}^{-1}$. Three samples were harvested every other day.

Growth phase (Short-term) experiments: The aim of this experiment was to investigate the growth phase of the growth curve under various light intensities. Three light intensities, 250 (average 246.1), 200 (average 203.0), and 100 (average100.1) $\mathrm{mol} \mathrm{m}^{-2} \mathrm{~s}^{-1}$ were tested. The experiments were conducted for 8 days. Two samples were harvested every other day. Ambient $\mathrm{CO}_{2}$ and elevated $\mathrm{CO}_{2}$ with two flow rates, 0.01041 gas ${ }^{-1}$ medium $\min ^{-1}$ (high flow rate) and 0.0021 gas $^{-1}$ medium $\min ^{-1}$ (low flow rate), were tested. Each experiment was repeated twice.

Prior to the oven-drying process, the sample was either centrifuged or filtered to separate the biomass from dissolved nutrients. Samples of SC2 were filtered with Whatman filter papers. SC2 grew quite well at an elevated temperature of $50^{\circ} \mathrm{C}$ and at elevated $\mathrm{CO}_{2}(5 \% \mathrm{v} / \mathrm{v}$ supplemented $)$.

Overall dry weight change is shown in Figures 20 and 21. Figure 20 shows the growth phase and Fig. 21 shows the stationary phase over day 20 . Figure 22 shows the changes in dry weights over time under three different light intensities. There were a few days of lag period, followed by the exponential growth phase. In additional experiments, it was observed that SC2 also successfully survived at the lower light intensities of 36.9 and $70.19 \mu \mathrm{mol} \mathrm{m}^{-2} \mathrm{~s}^{-1}$.

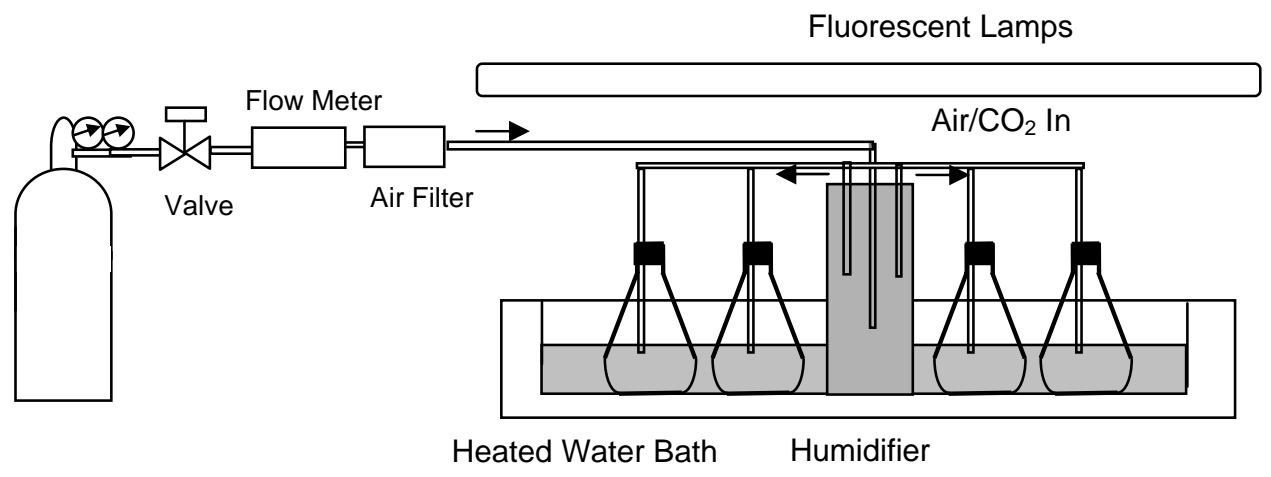

Fig. 19. Apparatus for the heated water-bath experiment with elevated $\mathrm{CO} 2$ concentration 


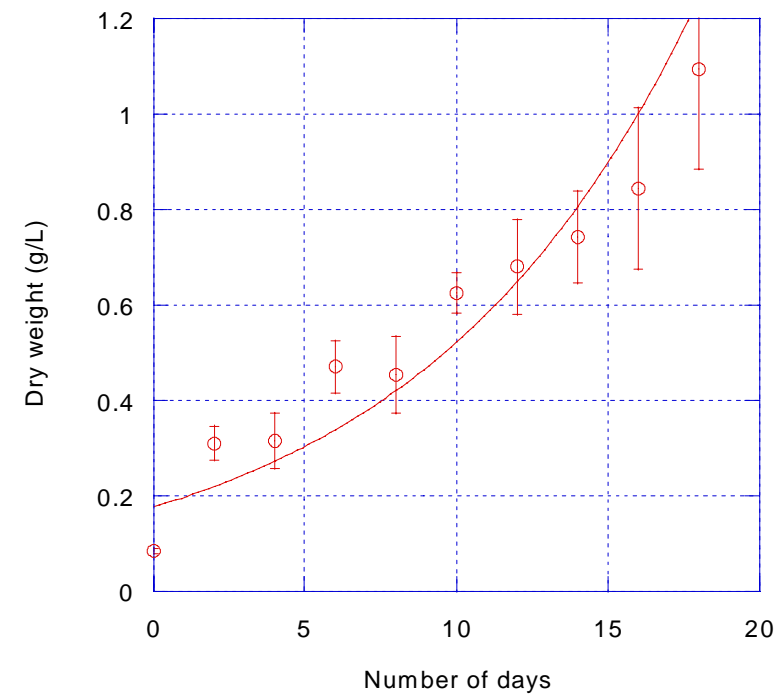

Fig. 20. Dry weight changes of SC2 over time at $5 \%(\mathrm{v} / \mathrm{v}) \mathrm{CO}_{2}$ and light intensity of $250 \mathrm{~mol} \mathrm{~m}^{-}$

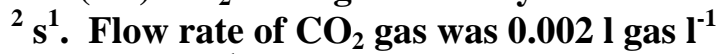
medium min $^{-1}$. Data are based on average of three samples. Error bars show standard deviations

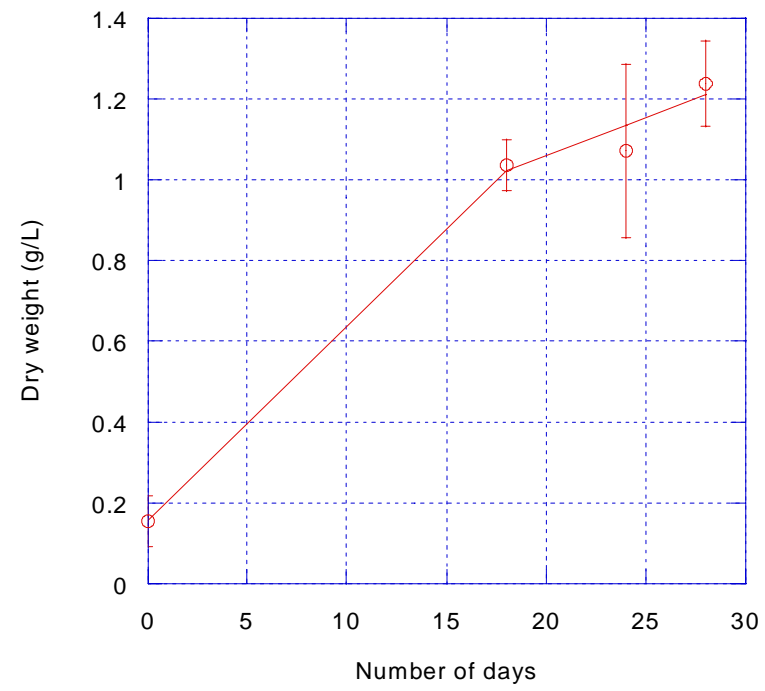

Fig. 21. Dry weight changes of SC2 over time at $5 \%(\mathrm{v} / \mathrm{v}) \mathrm{CO}_{2}$ and light intensity of $250 \mathrm{~mol} \mathrm{~m}^{-}$

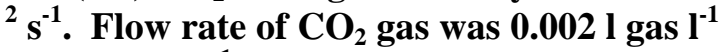
medium $\mathrm{min}^{-1}$. Data are based on average of three samples. Error bars show standard deviations.

The carbon assimilation rate was estimated based on the dry biomass data and the carbon analysis data. The carbon content of SC2 dried biomass was $41.1 \%$ with standard deviation of $1.3(n=6)$. Figure 23 shows the carbon assimilation rate for combinations of three light conditions and three $\mathrm{CO}_{2}$ conditions. The maximum carbon assimilation rate was $20.45 \mathrm{mgC} / \mathrm{L}$-day. The maximum was observed under 200 mol m-2 s- 1 and $5 \% \mathrm{CO}_{2}$ with a low flow rate condition. Note that elevated $\mathrm{CO}_{2}$ concentration enhanced carbon assimilation rates.

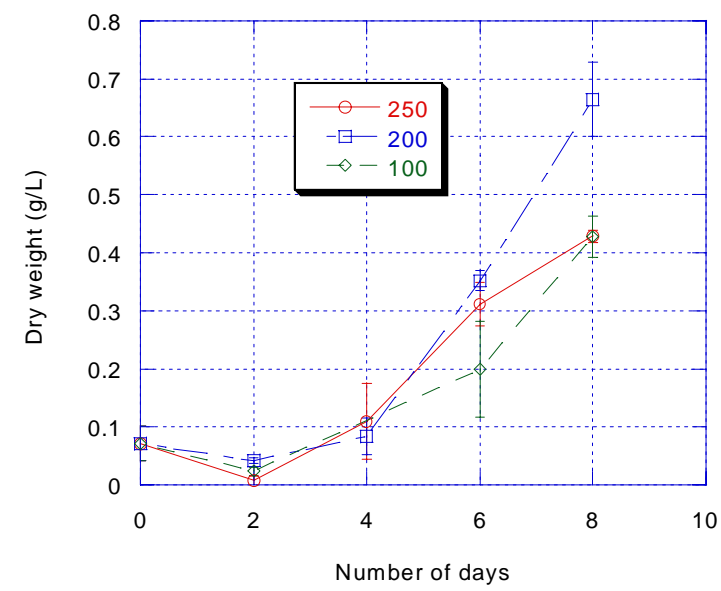

Fig. 22. Dry weight changes of SC2 over time for three light intensities in $\mathrm{mol} \mathrm{m}^{-2} \mathrm{~s}^{-1}$. Flow rate of $\mathrm{CO}_{2}$ gas was $0.002 \mathrm{l}_{\text {gas }} \mathrm{l}^{-1}$ medium $\mathrm{min}^{-1}$. Data are based on an average of two samples. Error bars show standard deviations. 


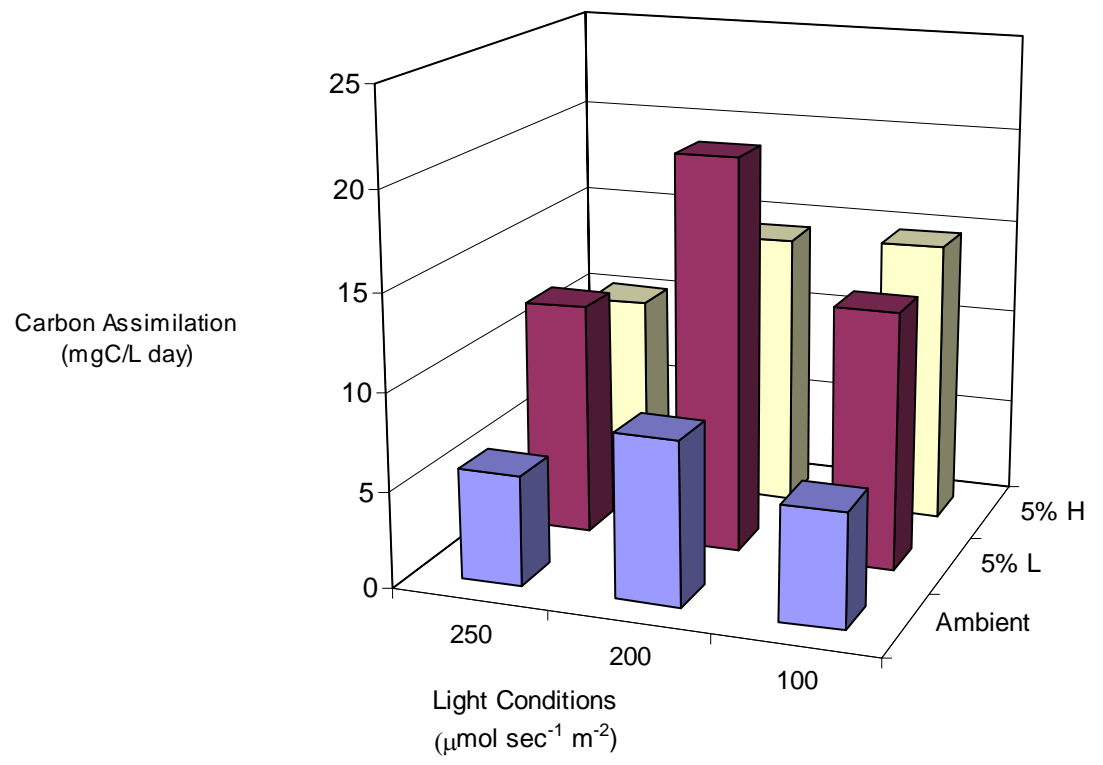

Fig. 23. Carbon assimilation rates of SC2 for three light intensities and three $\mathrm{CO}_{2}$ gas conditions. Data were based on average of two replications. Each replication had two samples.

\section{Demonstration of Bench-Top Lab-Scale Bioreactor}

A bench-top lab-scale photobioreactor for growing cyanobacteria for $\mathrm{CO}_{2}$ fixation was designed and constructed (Figures 24 and 25). The size of the reactor was $29.2 \mathrm{~cm} \mathrm{~W} \mathrm{x} 40 \mathrm{~cm} \mathrm{H} \mathrm{x} 61 \mathrm{~cm} \mathrm{~L}$ (or $111 / 2$ " W x 15 3/4" H x 24" L). A small pump (Beckett Corporation, Irving, Texas), with $227 \mathrm{~L} / \mathrm{hr}$ (60GH) capacity, was used for delivering the nutrient solution on top of the rectangular membrane onto which the cyanobateria attached and grew. The nutrient solution (BG-11) was delivered through a $1.27-\mathrm{cm}(1 / 2$-in ID) PVC pipe. Three rectangular membrane frames $(45.72 \mathrm{~cm} \mathrm{~W}$ x $25.40 \mathrm{~cm} \mathrm{H}$ or 18 " W x 10" H) as growing substrates or supports were enclosed in a transparent airtight enclosure. The piping system also served as the structure to hold the frames. A Plexiglas top cover was used to allow penetration of photosynthetic radiation. Air movement within the chamber was controlled using two DC fans (FBA12G, Panasonic) and a DC power supply. The air movement was regulated by simply changing the voltage supply. Under $12 \mathrm{~V}$ DC operation, the average wind speed at the center was $0.7 \pm 0.2 \mathrm{~m} / \mathrm{s}$. The temperature within a photobioreactor was controlled using a water bath (National Appliance Co., Portland, Oregon) and copper tubing.

\section{Discussion}

Certain species of Chlorella had been studied for both $\mathrm{CO}_{2}$ mitigation and for their commercial potential as a health food. The strain of Chlorella vulgaris (UTEX 259) used in this study, however, showed limited thermal adaptability, and presents a challenge in exposing such strain to direct flue-gas injection from an electric power plant. Previous studies reported that some strains of Chlorella are thermotolerant. For example, Chlorella pyrenoidosa can grow at $39{ }^{\circ} \mathrm{C}$. Hirata et al. (1996b) reported that an unidentified Chlorella sp. (UK001), which was isolated from a spring in Oh-ita prefecture, Japan, could grow at 40 ${ }^{\circ} \mathrm{C}$. Hanagata et al. (1992) also reported that an unidentified Chlorella sp. (strain K35), isolated from a Japanese fresh-water environment, could grow at $40{ }^{\circ} \mathrm{C}$, although there was a five-day lag before growth. 
This same species, however, failed to grow at $45^{\circ} \mathrm{C}$. Chlorella vulgaris (UTEX 259) used in this study apparently had a lower optimal temperature than those cited in the literature.

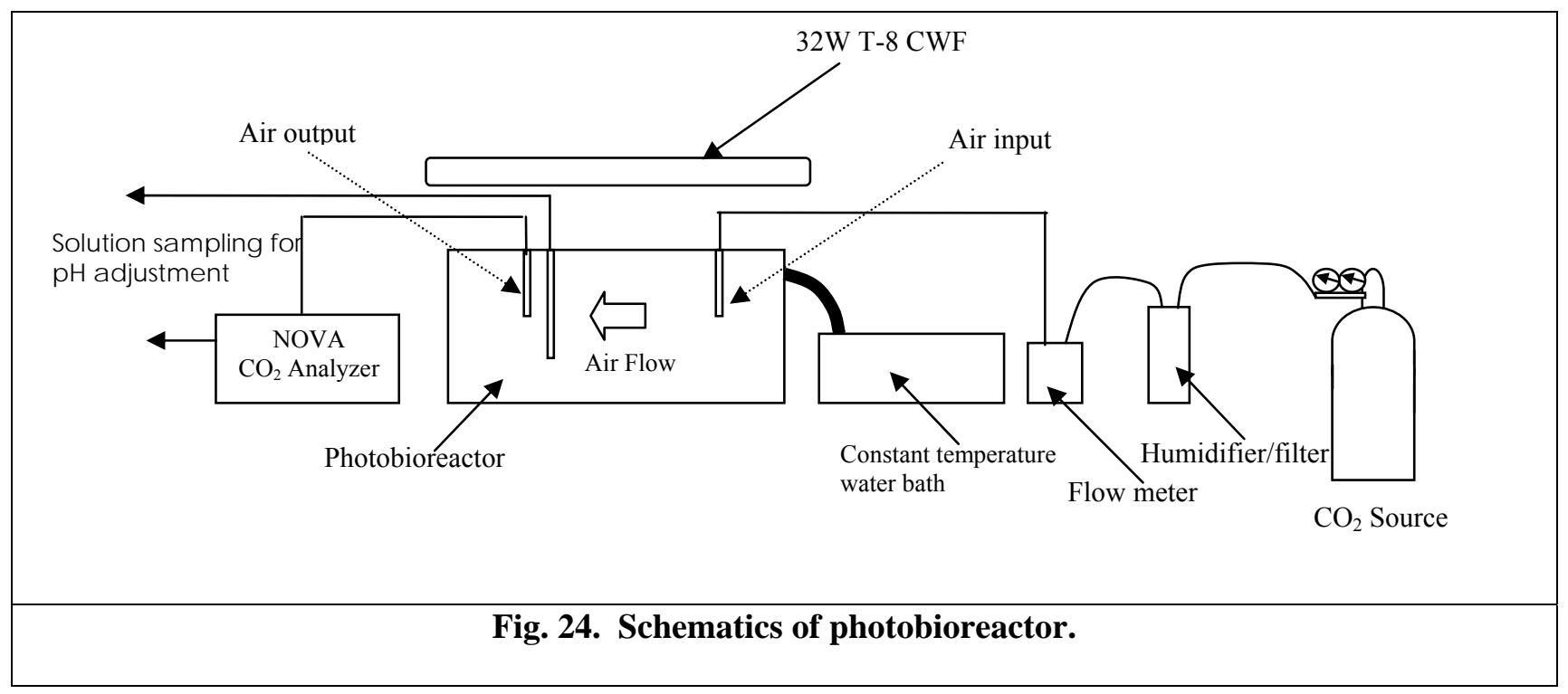

The thermophilic SC2 could grow very well at the elevated temperature of $50{ }^{\circ} \mathrm{C}$ and at elevated $\mathrm{CO}_{2}(5 \%$ $\mathrm{v} / \mathrm{v}$ supplemented). Elevated $\mathrm{CO}_{2}$ concentration enhanced $\mathrm{CO}_{2}$ assimilation rate. The species also exhibited high light adaptability, growing successfully under high light intensity $\left(246.1 \mu \mathrm{mol} \mathrm{m}^{-2} \mathrm{~s}^{-1}\right)$ and low light intensity $\left(36.9 \mu \mathrm{mol} \mathrm{m} \mathrm{m}^{-2} \mathrm{~s}^{-1}\right)$. The best light intensity was $200 \mu \mathrm{mol} \mathrm{m} \mathrm{m}^{-2} \mathrm{~s}^{-1}$ regardless of $\mathrm{CO}_{2}$ concentration and flow rate conditions. This result is useful in determining the best lighting strategy to be used for a $\mathrm{CO}_{2}$-mitigation photobioreactor

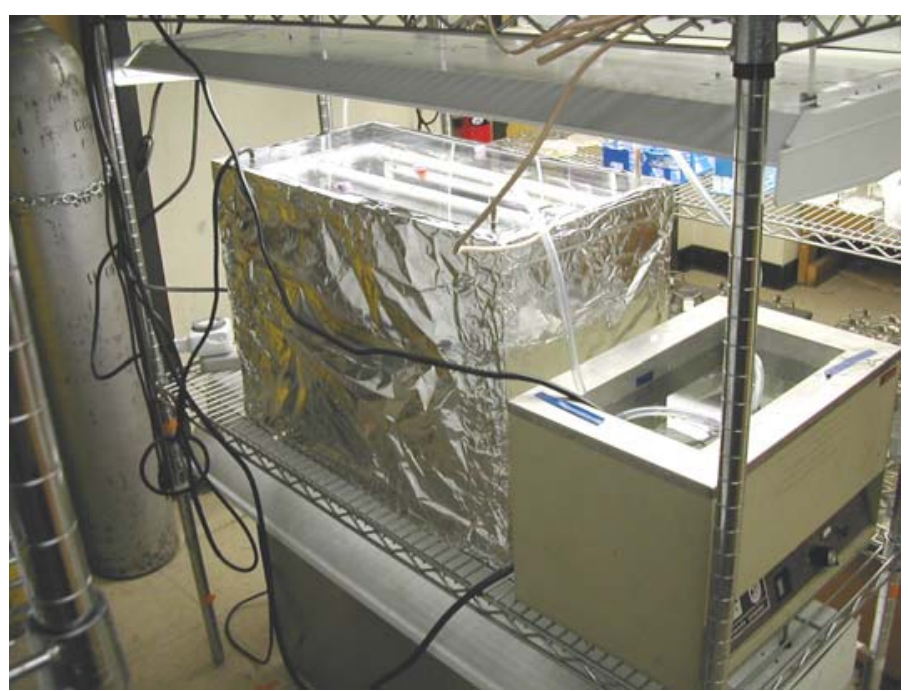

Fig. 25. Operation of membrane photobioreactor. 


\section{Conclusions}

The thermal adaptability of the strain of Chlorella vulgaris (UTEX 259) used in this study was limited. The strain failed to survive at the elevated temperature of $50{ }^{\circ} \mathrm{C}$. The strain even showed limited growth at $35^{\circ} \mathrm{C}$.

$\mathrm{SC} 2$ could successfully grow at the elevated temperature $\left(50^{\circ} \mathrm{C}\right)$ and at elevated $\mathrm{CO}_{2}(5 \% \mathrm{v} / \mathrm{v}$ supplemented). Elevated $\mathrm{CO}_{2}$ concentration enhanced $\mathrm{CO}_{2}$ assimilation rate. The species also had high light adaptability, growing successfully at high light intensity $\left(246.1 \mu \mathrm{mol} \mathrm{m} \mathrm{m}^{-2}\right)$ and low light intensity $\left(36.9 \mu \mathrm{mol} \mathrm{m} \mathrm{m}^{-1}\right)$. The best light intensity was $200 \mu \mathrm{mol} \mathrm{m}{ }^{-2} \mathrm{~s}^{-1}$ regardless of $\mathrm{CO}_{2}$ concentration and flow rate conditions.

The maximum $\mathrm{CO}_{2}$ assimilation rate during growth phase was $20.45 \mathrm{mgC} / \mathrm{L}$-day.

The thermophilic species tested had the ability to assimilate $\mathrm{CO}_{2}$ at the elevated temperature $\left(50^{\circ} \mathrm{C}\right)$ and at the elevated $\mathrm{CO}_{2}\left(5 \% \mathrm{v} / \mathrm{v}\right.$ supplemented). The results demonstrated clear potential for biological $\mathrm{CO}_{2}$ mitigation using thermophilic cyanobacteria with hybrid solar photobioreactor.

The membrane photobioreactor design, construction, and operation were discussed in Part I, the Technical Feasibility section. Further studies on membrane materials, initial biomass loading, and nutrient circulation rates are needed.

\section{DESCRIPTION OF TRNSYS SYSTEM MODEL (Contributed by UW)}

The TRNSYS (TraNsient SYStem Simulation program, Klein et al., 2000) Hybrid Lighting System (HLS) Model consisted of interconnected component models that included a weather file, radiation processors, hybrid lighting model, building model, building schedules, utility rate schedules, and output components. Simulation results include the annual energy and monetary savings associated with a hybrid lighting system as well as colorimetric indices, the correlated color temperature (CCT), and the colorrendering index (CRI).

TMY2 weather files are used with SMARTS2 (Simple Model for the Atmospheric Radiative Transfer of Sunshine, Gueymard 2000) in order to generate the spectral power density (SPD) of incident radiation on the collector for each hour of the year. This SPD is attenuated by the spectral and wideband transmittances of the collecting and cold mirrors, the fiber entrance region, the fiber itself, and the luminaires. The luminous and radiant power provided to the workspace is calculated from the SPD that remains after passing through these components.

Within TRNSYS, the light output from the hybrid lighting system model provides an input to the building model. The building is modeled using the Type 56 multi-zone building model, which is a FORTRAN subroutine designed specifically to provide a detailed thermal model of buildings. The Type 56 model consists of two windowless $2500 \mathrm{~m}^{2}$ zones; one zone uses conventional electric lighting exclusively whereas the other zone pairs conventional electric lighting with light delivered by the HLS. Identical schedules in the two zones simulate the heating, cooling, and ventilation of a typical mixed-use environment.

Additional gains in the model account for the people, computers, and lights in the building. Cooling in the building is supplied using a chiller with an assumed constant COP of 3.0 and heating loads are met using 
an assumed $80 \%$ efficient natural gas furnace. Local utility rate schedules are used to compute energy costs for the two zones of the building model; the difference in the energy cost represents the energy savings associated with the hybrid lighting system.

The simulation uses a heating set point of $20^{\circ} \mathrm{C}$ with a night setback of $17^{\circ} \mathrm{C}$. Cooling is active at $26^{\circ} \mathrm{C}$ and above. Relative humidity within the building is allowed to float between 30 and $60 \%$. Illumination levels within the building are set to 500 Lux which is the IESNA recommended lighting level for general office work. Occupancy schedules model a typical 8 am to $5 \mathrm{pm}$ work week. Infiltration and ventilation rates are based on information provided in ASHRAE 62-2001. Rate schedules from utilities near the various locations are used to determine the time variant prices of natural gas and electricity.

Eight HLS $1.7 \mathrm{~m}^{2}$ modules are used to collect the beam normal radiation. During clear sky conditions, this collecting area provides about half of the lumens needed to illuminate the workspace. Thermal performance and economic assessments of the system in different U.S. climates are provided by Schlegel (2003) and Schlegel et al. (2003, 2004)

An advantage of hybrid lighting over artificial lighting is that the spectral distribution in the visible wavelengths is essentially the same as sunlight. Perceived colors of surfaces are affected by the spectral distribution of the light source and true colors are observed under sunlight. The TRNSYS Hybrid Lighting System Model was revised so that two colorimetric indices that are pertinent to indoor illumination, namely the correlated color temperature (CCT) and color-rendering index (CRI), are predicted by the model. Detailed results of the CCT and CRI calculations are provided by Burkholder et al. 2004 and Burkholder 2004.

A key component of the HSL system is the fiber optic bundle (FOB) that transmits the light from the collector to the luminaire. The observed thermal failure of the FOB when exposed to concentrated sunlight has motivated the development of a predictive thermal model of the heat transfer within this component. The model has been verified experimentally against temperature measurements obtained in the lab under controlled conditions. The model can be used as a design tool to evaluate alternative thermal management strategies.

The FOB is constructed of 126, 2.9 mm diameter, polymethylmethacrylate (PMMA) optical fibers, each clad in a 50-micron thick layer of fluorinated polymer. The fibers are packed together to form a circular bundle. The packed fibers consist of PMMA, cladding and air gaps, and results in a porous FOB face that is illuminated by concentrated radiation from the sun. The incident solar radiation on the face of the FOB contributes to two forms of volumetric heat generation within the FOB. The first is due to the absorption of the radiation that is transmitted through the PMMA fibers, and the second is due to radiation that strikes the air gap or cladding. In either case, the radiation is locally absorbed at a rate that is proportional to its local intensity, and, therefore, the resulting volumetric heating must be exponential with some characteristic length; the characteristic length depends on the absorption characteristics of the optical path which is different for the light that is trapped in the fibers compared with the light that strikes the cladding or air gap. The absorption of radiation that is transmitted through the PMMA fibers contributes a low level volumetric generation with a characteristic length of approximately $24 \mathrm{~m}$, while the absorption of radiation that is traveling through the air gaps between the fibers contributes a high level of heat generation that is concentrated near the face of the FOB, with a characteristic length of only $2 \mathrm{~cm}$. A detailed description of the thermal FOB model can be found in Cheadle et al. 2005 and Cheadle 2006.

The thermal loading due to the absorption of radiation that is traveling through the air gaps between the fibers is of highest concern and can be managed in two general ways: 1) reduce the amount of incident radiation on the air gaps between fibers, and 2) create a more efficient thermal path that allows the heat 
generated at the face of the FOB to be removed via convection and/or conduction. Thermal management strategies are discussed in more detail in Cheadle 2006.

\section{System Analyses}

The hybrid lighting system using TRNSYS consists of two major components: the building component and the hybrid lighting component. The TRNSYS type 56 building component was configured to simulate a large multi-use environment such as a retail or office space. The hybrid lighting component model uses the incoming beam radiation and spectral properties of the hybrid lighting system to determine the light and electricity benefits produced. The light 'produced' by the hybrid lighting component provides an input to the building model that is used to calculate the impact that the hybrid lighting technology has upon building loads. An economic model is included in the TRNSYS simulation that uses local utility rate schedules to translate the hybrid lighting impacts upon the building lighting, heating, and cooling loads into monetary savings. The energy savings predicted by TRNSYS are then used to determine a breakeven capital cost for the hybrid lighting system.

For detailed TRNSYS simulation results consult Schlegel et al. 2003, Schlegel 2003, and Schlegel et al. 2004. The TRNSYS simulations results are summarized in the following sections.

Table 3 summarizes TRNSYS results for the locations investigated. Of these, the location where the installation of a hybrid lighting system provides the largest economic advantage was Honolulu, HI; Tucson, AZ was found to be the best location within the continental United States. Using the predicted annual savings over a 10-year analysis period, the breakeven capital cost of hybrid lighting modules in these locations are $\$ 2,410$ and $\$ 1,885$ per $1.7 \mathrm{~m}^{2}$ module.

Table 3. Economic summary of TRNSYS simulations for active collector area of $1.7 \mathbf{~ m}^{2}$.

\begin{tabular}{|c|c|c|c|c|}
\hline Location & $\begin{array}{c}\text { Anmual } \\
\text { Savings } \\
{[\$ / \text { module }]}\end{array}$ & $\mathbf{P}_{1} / \mathbf{P}_{2}$ & $\begin{array}{c}\text { Average } \\
\text { Energy Rate, } \\
\text { 8am-5pm, } \\
\text { Summer } \\
\text { [\$/kWh] } \\
\end{array}$ & $\begin{array}{c}\text { BECC } \\
{[\$ / \text { module }]}\end{array}$ \\
\hline Honolulu, HI & $\$ 395$ & $\begin{array}{l}6.1 \\
7.7 \\
8.5 \\
\end{array}$ & 0.165 & $\begin{array}{l}\$ 2,410 \\
\$ 3,042 \\
\$ 3,358 \\
\end{array}$ \\
\hline Tucson, AZ & $\$ 327$ & $\begin{array}{l}6.1 \\
7.7 \\
8.5 \\
\end{array}$ & 0.137 & $\begin{array}{l}\$ 1,885 \\
\$ 2,518 \\
\$ 2,780 \\
\end{array}$ \\
\hline Reno, NV & $\$ 199$ & $\begin{array}{l}6.1 \\
7.7 \\
8.5 \\
\end{array}$ & 0.083 & $\begin{array}{l}\$ 1,214 \\
\$ 1,532 \\
\$ 1,692 \\
\end{array}$ \\
\hline Seatlle, WA & $\$ 76$ & $\begin{array}{l}6.1 \\
7.7 \\
8.5 \\
\end{array}$ & 0.059 & $\begin{array}{l}\$ 464 \\
\$ 585 \\
\$ 646 \\
\end{array}$ \\
\hline Madison, WI & $\$ 68$ & $\begin{array}{l}6.1 \\
7.7 \\
8.5 \\
\end{array}$ & 0.056 & $\begin{array}{l}\$ 415 \\
\$ 524 \\
\$ 578 \\
\end{array}$ \\
\hline Atlanta, GA & $\$ 48$ & $\begin{array}{l}6.1 \\
7.7 \\
8.5 \\
\end{array}$ & 0.055 & $\begin{array}{l}\$ 293 \\
\$ 370 \\
\$ 408 \\
\end{array}$ \\
\hline
\end{tabular}

Using longer economic analysis periods results in higher break-even capital costs of $\$ 3,042$ and $\$ 2,518$ for a 20 -year period and $\$ 3,358$ and $\$ 2,780$ for a 30 -year period. These costs represent the maximum total cost that could be invested in a hybrid lighting module without having a negative life-cycle cost over the economic period considered. The hybrid lighting module includes these major components: concentrating collector (active collecting area of $1.7 \mathrm{~m}^{2}$ ), two-axis tracking equipment, secondary element, TPV 
assembly, optical fibers ( $\sim 7$ meters per module), luminaires, and controls. To manufacture, ship, and install a hybrid lighting module for less than $\$ 2,800$ would be extremely challenging.

The current design of the hybrid solar lighting system features a $1.0 \mathrm{~m}^{2}$ dish as opposed to the $1.7 \mathrm{~m}^{2}$ dish size considered in Table 3. Therefore, the results of Table 3 have been recalculated for an active collecting area of $1.0 \mathrm{~m}^{2}$ and these updated results are displayed in Table 4 . The total active collecting area (\# of modules multiplied by the area per module) remains the same for both tables. Because a greater number of $1.0 \mathrm{~m}^{2}$ modules are needed to maintain the same total active collecting area, both the annual savings and the break-even capital cost are reduced.

Table 4. Economic summary of TRNSYS simulations for active collector area of $1.0 \mathbf{~ m}^{2}$.

\begin{tabular}{|c|c|c|c|c|}
\hline Location & $\begin{array}{c}\text { Annual } \\
\text { Savings } \\
{[\$ / \text { module }]}\end{array}$ & $\begin{array}{c}\text { Analysis } \\
\text { Period } \\
\text { [yrs] }\end{array}$ & $\mathbf{P}_{1} / \mathbf{P}_{2}$ & $\begin{array}{c}\text { BECC } \\
{[\$ / \text { module }]}\end{array}$ \\
\hline Honolulu, HI & $\$ 212$ & $\begin{array}{l}10 \\
20 \\
30\end{array}$ & $\begin{array}{l}6.1 \\
7.7 \\
8.5\end{array}$ & $\begin{array}{l}\$ 1300 \\
\$ 1633 \\
\$ 1809\end{array}$ \\
\hline Tucson, AZ & $\$ 169$ & $\begin{array}{l}10 \\
20 \\
30 \\
\end{array}$ & $\begin{array}{l}6.1 \\
7.7 \\
8.5 \\
\end{array}$ & $\begin{array}{l}\$ 1037 \\
\$ 1304 \\
\$ 1444 \\
\end{array}$ \\
\hline Reno, NV & $\$ 102$ & $\begin{array}{l}10 \\
20 \\
30\end{array}$ & $\begin{array}{l}6.1 \\
7.7 \\
8.5\end{array}$ & $\begin{array}{l}\$ 623 \\
\$ 783 \\
\$ 868\end{array}$ \\
\hline Seatlle, WA & $\$ 38$ & $\begin{array}{l}10 \\
20 \\
30\end{array}$ & $\begin{array}{l}6.1 \\
7.7 \\
8.5\end{array}$ & $\begin{array}{l}\$ 236 \\
\$ 297 \\
\$ 329\end{array}$ \\
\hline Madison, WI & $\$ 34$ & $\begin{array}{l}10 \\
20 \\
30\end{array}$ & $\begin{array}{l}6.1 \\
7.7 \\
8.5\end{array}$ & $\begin{array}{l}\$ 210 \\
\$ 264 \\
\$ 292\end{array}$ \\
\hline Atlanta, GA & $\$ 24$ & $\begin{array}{l}10 \\
20 \\
30\end{array}$ & $\begin{array}{l}6.1 \\
7.7 \\
8.5\end{array}$ & $\begin{array}{l}\$ 149 \\
\$ 187 \\
\$ 207\end{array}$ \\
\hline
\end{tabular}

\section{OVERALL PROJECT SUMMARY STATEMENT}

This project can be declared a success:

1) It has demonstrated that concentrated visible sunlight can be collected and transported efficaciously to a luminaire using polymer fiber optics and the infrared solar energy can be separated and directed to a thermophotovolataic array for electrical power generation.

2) It has demonstrated that sunlight can be integrated with conventional lighting systems to reduce energy during sunlight hours and provide a very desirable light quality at the same time.

3) It has demonstrated that concentrated sunlight can be used efficaciously in a $\mathrm{CO}_{2}$-mitigation photobioreactor.

4) The HSL system developed in part by this project is being commercialized by a spin off company.

5) The photobioreactor technology developed in part by this project has been licensed to a company that intends to exploit its use in developing biofuels. 
6) A new biofuels initiative has been funded by the State of Utah will use both the sunlight harvesting system and the bioreactor concept as part of a biorefinery development effort to produce biofuels and bioproducts in environmentally responsive ways.

7) The performance of the Beta HSL System (third generation) has essentially met the performance targets: 50,000 lumens (peak) per square meter of collected light to interior space. The project goal was $56 \%$ for overall system efficiency; $50 \%$ of available lumens in incident sunlight delivered to interior spaces were achieved.

8) Although a cost target of $\$ 2,000 / \mathrm{m}^{2}$ of collected sunlight was set based on TRNSYS performance and cost models, the realities of the market will determine whether its cost is affordable. Nonetheless, a well defined path for a low cost system has been presented.

9) The research and its results are well documented in the open literature and in theses and a dissertation.

10) A comprehensive review of potential niche applications has been presented. 


\section{MAJOR CONTRIBUTIONS OF EACH PARTNER}

\begin{tabular}{|c|c|}
\hline Partner & Major Contributions \\
\hline $\begin{array}{l}\text { University of Nevada/ } \\
\text { Utah State University }\end{array}$ & $\begin{array}{l}>\text { Project management } \\
>\text { Ray trace models } \\
>\text { Thermal photovoltaic (TPV) integration and testing } \\
>\text { Endurance testing of fiber optics } \\
>\text { Component modeling and testing } \\
>\text { System testing }\end{array}$ \\
\hline Honeywell Technology Center & $\begin{array}{l}\text { Shortly after the award, the PI at Honeywell transferred to a new } \\
\text { position and since Honeywell's contribution was scheduled for the } \\
\text { end of second year, this task was reassigned within the team. }\end{array}$ \\
\hline JX Crystals, Inc. & $\begin{array}{l}>\text { Designed and fabricated the TPV module } \\
>\end{array}$ \\
\hline Oak Ridge National Lab & $\begin{array}{l}>\text { HSL hardware development and testing } \\
>\text { Designed and built Benchmark HSL system } \\
>\text { Lead on developing Beta HSL system } \\
>\text { Integration of HSL with florescent luminaire } \\
>\text { Developed laboratory demonstrations } \\
>\text { Optical fiber transmittance testing } \\
>\text { Ray trace models }\end{array}$ \\
\hline Ohio University & $\begin{array}{l}>\text { Lab scale photobioreactor development and testing } \\
>\text { Bioreactor feasibility analysis and tests }\end{array}$ \\
\hline $\begin{array}{l}\text { Rensselaer Polytechnic } \\
\text { Institute - Lighting Research } \\
\text { Center }\end{array}$ & $\begin{array}{l}>\text { Ray trace analysis } \\
>\text { Luminaire light distribution } \\
>\text { Comprehensive literature review of the affects of solar light on } \\
\text { human productivity } \\
>\text { Identification of potential niche market applications for HSL }\end{array}$ \\
\hline $\begin{array}{l}\text { Science Applications } \\
\text { International Corporation }\end{array}$ & $\begin{array}{l}>\text { Low cost solar system development } \\
>\text { Evaluation of primary mirror options }\end{array}$ \\
\hline 3M Company & $\begin{array}{l}\text { Fiber optic material properties } \\
\text { Supplied the } 12 \mathrm{~mm} \text { fiber optics and light diffuser rods for hybrid } \\
\text { luniaire }\end{array}$ \\
\hline TVA Public Power Institute & $>$ Provided critical cost share \\
\hline University of Arizona & $\begin{array}{l}>\text { Micro algae screening tests for } \mathrm{CO}_{2} \text { mitigation } \\
>\text { Bioreactor environment testing and analysis } \\
>\end{array}$ \\
\hline University of Wisconsin & $\begin{array}{l}\text { TRNSYS simulation models for HSL system and components to } \\
\text { predict HSL performance for commercial buildings in several } \\
\text { locations } \\
>\text { Economic viability analysis }\end{array}$ \\
\hline
\end{tabular}




\section{REFERENCES}

Bacastow, R., and Dewey, R. (1996) Effectiveness of $\mathrm{CO}_{2}$ sequestration in the post-industrial ocean, Energy Conversion and Management, 37(6-8),1079-1086.

Brock, T.D. (1978) Thermophilic Microorganisms and Life at High Temperatures, Springer-Verlag, New York, USA.

Burkholder, F.W. (2004) TRNSYS Modeling of a Hybrid Lighting System: Energy Savings and Colorimetry Analysis, M.S. Thesis, Solar Energy Laboratory, University of Wisconsin - Madison, http://sel.me.wisc.edu/publications/theses/theses2.html

Burkholer, F.W., et al. (2004) TRNSYS Modeling of a Hybrid Lighting System: Building Energy Loads and Chromaticity Analysis. In Proceedings of ASES Annual Conference, Campbell-Howe, R. (Ed), pp. 963-968, Portland, Oregon.

Cheadle, M.J. (2006) A Thermal Model of a Fiber Optic Bundle For a Hybrid Solar Lighting System, M.S. Thesis, Solar Energy Laboratory, University of Wisconsin - Madison

Cheadle, M.J., et al. (2005) A Thermal Model Of a Fiber Optic Bundle For a Hybrid Solar Lighting System. To be published in Proceedings of IMECE: 2005 ASME International Mechanical Engineering Congress \& Exposition, Orlando, Florida.

Cooksey, K.E., and Wigglesworth-Cooksey, B. (1995) Aquatic Microbial Ecol., 9, 87-96.

Fisher, A., (1961) Solar Energy Research, University of Wisconsin Press, Madison, WI, USA, 185-189.

Greenberg, A.A., J.J. Connors and D. Jenkins (eds.). Standard Methods for the Examination of Water and Wastewater. 15th ed. p. 1134. American Public Health Association, Washington D.C.

Gueymard, C. (2000), Prediction and Performance Assessment of Mean Hourly Global Radiation, Solar Energy, 68, No. 3

Hanagata, N. T. Takeuchi, Y. Fukuju, D.J. Barnes and I. Karube. (1992) Tolearnce

of Microalgae to High CO2 and High Temperature. Photochemistry. 31(10):

3345-3348.

Hirata, S., Hayashitani, M., Taya, M., and Tone, S. (1996a) Journal of Fermentation and Bioengineering 81, 470-472.

Hirata, S., M. Taya and S. Tone. (1996b) Characterization of Chlorella Cell

Cultures in Batch and Continuous Operations Under a Photoautotrophic

Condistion. Journal of Chemical Engineering of Japan. 29(6): 953-959.

Jepson, et al., 1993; Jepson, W.P., and Taylor, R.E. (1993) Int. J. Multiphase Flow 19 (3) 411-420.

Kajiwara, S., Yamada, H., Ohkuni, N., and Ohtaguchi, K. (1997) Energy Conversion and Management 38(Supplemental Issue), 529-532. 
Klein, S.A., et al. (2000), TRNSYS, A Transient Simulation Program, Solar Energy Laboratory, University of Wisconsin - Madison

Ohtaguchi, K., Kajiwara, S., Mustaqim, D., Takahashi, N., (1997) Energy Conversion and Management 38(Supplemental Issue), 523-528.

Schlegel, G.O. (2003) A TRNSYS Model of a Hybrid Lighting System, M.S. Thesis, Solar Energy Laboratory, University of Wisconsin - Madison, http://sel.me.wisc.edu/publications/theses/

theses $2 . h t m l$

Schlegel, G.O., et al. (2003) A TRNSYS Model of a Full Spectrum Hybrid Lighting System. In Proceedings of ISES Solar World Congress, Göteborg, Sweden.

Schlegel, G.O., et al. (2004). Analysis of a Full Spectrum Hybrid Lighting System. Solar Energy 76, No. 4, 359-368.

\section{DISTRIBUTION}

$>$ NETL AAD Document Control

$>$ David J. Bayless, Ohio University

$>$ William Beckman, University of Wisconsin

$>$ Clinton Berry, TN Dept. of Economic \& Community Dev. Energy Division

$>$ James Brodrick, DOE

$>$ Joel S. Chaddock, NETL

$>$ Joel L. Cuello, University of Arizona

$>$ Roger Davenport, Science Applications International Corporation

$>$ David R. Dinse, TVA Public Power Institute

$>$ Duncan Earl, Sunlight Direct, LLC

$>$ Lewis Fraas, JX Crystals Inc

$>$ Don Holms, 3M

$>$ Jason B. Keyes, JX Crystals Inc.

$>$ Sandy Klein, University of Wisconsin

$>$ Pete Konesky, Nevada Energy Office

$>$ Jeff Muhs, Oak Ridge National Laboratory

$>$ Nadarajah Narendran, Rensselaer Polytechnic Institute

$>$ Lew Pratsch. DOE

$>$ Ramesh Raghaven, RPI

$>$ Jennifer Sahlin, 3M

$>$ Robert Schnell, Honeywell Laboratories

$>$ Glenn Strahs, DOE

$>$ Robin W. Taylor, Science Applications International Corporation

$>$ Melissa Vos Lapsa, ORNL

$>$ Frank "Tex" Wilkins. DOE 